Florida International University FIU Digital Commons

\title{
Hegel's Critique of Contingency in Kant's Principle of Teleology
}

Kimberly Zwez

kzwez001@fiu.edu

DOI: $10.25148 /$ etd.FI14040885

Follow this and additional works at: https://digitalcommons.fiu.edu/etd

Part of the Continental Philosophy Commons, and the Religious Thought, Theology and Philosophy of Religion Commons

\section{Recommended Citation}

Zwez, Kimberly, "Hegel's Critique of Contingency in Kant's Principle of Teleology" (2014). FIU Electronic Theses and Dissertations. 1194.

https://digitalcommons.fiu.edu/etd/1194 


\section{FLORIDA INTERNATIONAL UNIVERSITY}

Miami, Florida

\section{HEGEL'S CRITIQUE OF CONTINGENCY IN KANT'S PRINCIPLE OF TELEOLOGY}

A thesis submitted in partial fulfillment of

the requirements for the degree of

MASTER OF ARTS

in

RELIGIOUS STUDIES

by

Kimberly Zwez 
To: Dean Kenneth G. Furton

College of Arts and Sciences

This thesis, written by Kimberly Zwez, and entitled Hegel's Critique of Contingency in Kant's Principle of Teleology having been approved in respect to style and intellectual content is referred to you for judgment.

We have read this thesis and recommend that it be approved

\begin{tabular}{rr}
\hline Christine Gudorf \\
\hline Kenneth Rogerson \\
\hline Whitney Bauman, Major Professor
\end{tabular}

Date of Defense: March 26, 2014

This thesis of Kimberly Zwez is approved.

$\begin{array}{r}\begin{array}{r}\text { Dean Kenneth G. Furton } \\ \text { College of Arts and Sciences }\end{array} \\ \hline \begin{array}{r}\text { Dean Lakshmi N. Reddi } \\ \text { University Graduate School }\end{array}\end{array}$

Florida International University 2014 


\section{DEDICATION}

I would like to dedicate this project to my mentor at Florida International University, Daniel Alvarez, Professor of Religious Studies. Attending his lecture series on Hegel and his successors has provided me with the background needed for this research, as well as given me a solid foundation to pursue further work in philosophy. Thanks Danny for encouraging me to study German language in Germany, for your moral support and guidance, and most of all, for a challenging intellectual exchange. 


\section{ACKNOWLEDGMENTS}

First and foremost, I owe a great deal to my parents and family and for their continuous support and encouragement during my entire academic career. I would especially like to thank the members of my committee for their continuous feedback on my research. My major professor Dr. Whitney Bauman has been a mentor to me for many years and has challenged me to think about how the philosophical dilemmas facing Kant and Hegel play a role in the broader context of the history of philosophy. His feedback and guidance throughout the writing process has been stimulating and invaluable to me. Dr. Christine Gudorf has been especially helpful in carefully reading my drafts and providing me with feedback which allowed my work to appear polished and intelligible. Finally, my conversations with Dr. Kenneth Rogerson have challenged my views and forced me to dig deeper into Kantian philosophy. I would also like to acknowledge two professors from outside Florida International University. Dr. Paul Guyer, professor at Brown University, has taken his time to answer my emails with detailed responses which really clarified some of the nuances in Kant's Critiques. Dr. Sally Sedgwick, professor at University of Illinois, has also been helpful in guiding me in the initial stages of my research. Our exchange has helped shape my overall view of Hegelian philosophy. 


\section{ABSTRACT OF THE THESIS \\ HEGEL'S CRITIQUE OF CONTINGENCY IN KANT'S PRINCIPLE OF \\ TELEOLOGY}

by

Kimberly Zwez

Florida International University, 2014

Miami, Florida

\section{Professor Whitney Bauman, Major Professor}

This research is a historical-exegetical analysis of Hegel's reformulation of Kant's regulative principle of teleology into a constitutive principle. Kant ascribes teleology to the faculty of reflective judgment where it is employed as a guide to regulate inquiry, but does not constitute actual knowledge. Hegel argues that if Kant made teleology into a constitutive principle then it would be a much more comprehensive theory capable of overcoming contingency in natural science, and hence, bridging the gap between natural science and theology. In this paper I argue that Hegel's defense of the transition from natural science to theology is ultimately unsuccessful because it is built upon on an instinct of reason which is the instinctive feature of human rationality to transition beyond the contingency remaining in our empirical understanding of nature to a theological understanding of nature in which all aspects of nature are necessarily related. 


\section{TABLE OF CONTENTS}

CHAPTER

PAGE

INTRODUCTION

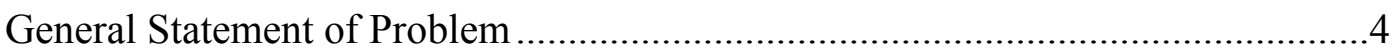

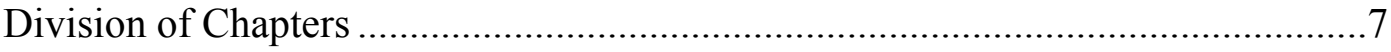

CHAPTER I. TWO TYPES OF CONTINGENCY ASSOCIATED WITH THE

DISCURSIVE INTELLECT ......................................................................... 12

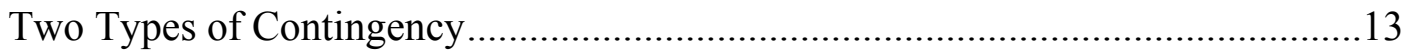

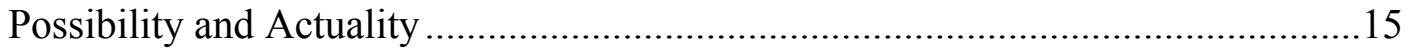

CHAPTER II. CONTINGENCY BETWEEN REASON AND NATURE .......................18

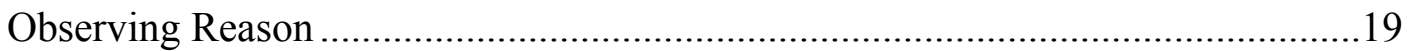

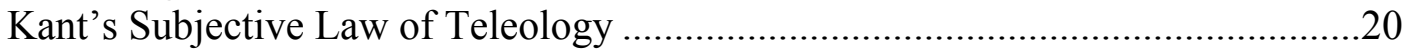

Referent of Teleology: the Understanding ............................................23

Objective Contingency of Teleology ....................................................24

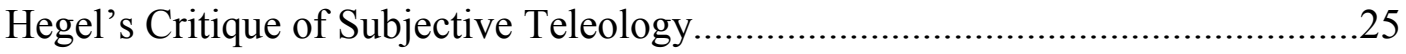

Objective Law of Teleology ............................................................28

CHAPTER III. CONTINGENCY IN EMPIRICAL LAWS: REASON'S DEMAND FOR

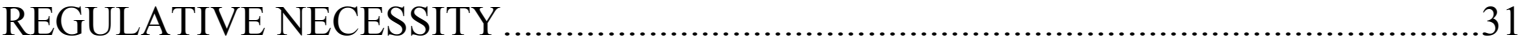

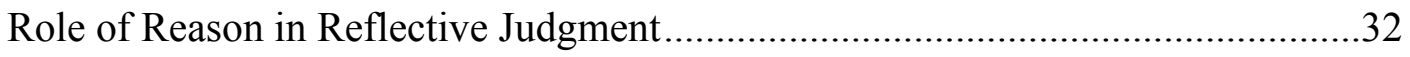

Objective Contingency and Subjective Necessity ..............................................34

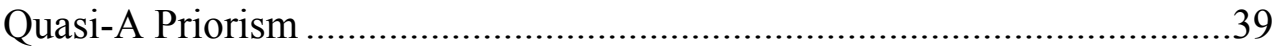

Unresolved Contradiction of Necessity and Contingency ..................................40

CHAPTER IV. CONTINGENCY OF PARTICULARS: REASON'S DEMAND FOR

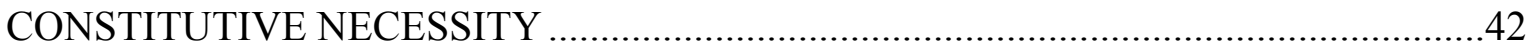

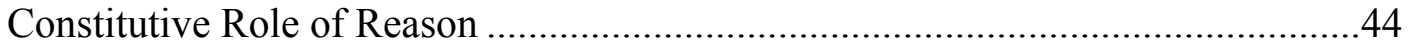

Objective Contingency and Objective Necessity................................................46

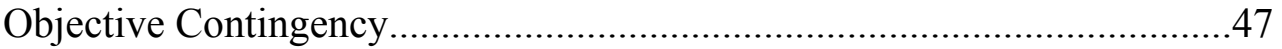

The Instinct of Reason and Objective Necessity .....................................49

Solution to the Contradiction of Necessity and Contingency? .............................51

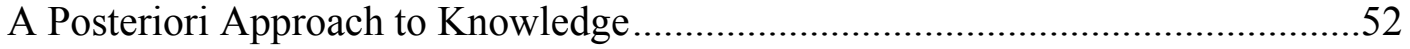

CHAPTER V. THE ROLE OF HEGELIAN TELEOLOGY IN NATURAL

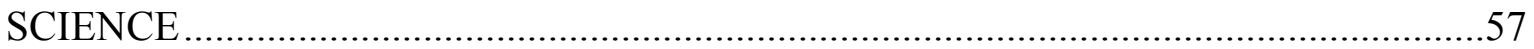

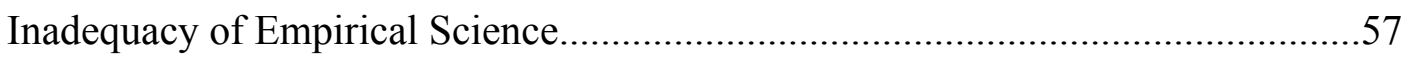

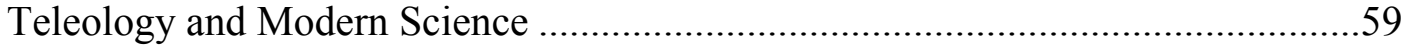

CHAPTER VI. INADEQUACY IN HEGEL'S LEAP FROM NATURAL SCIENCE TO

THEOLOGY 


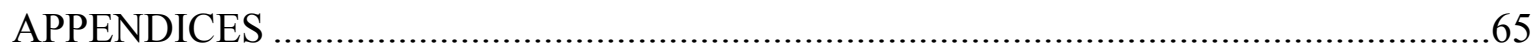

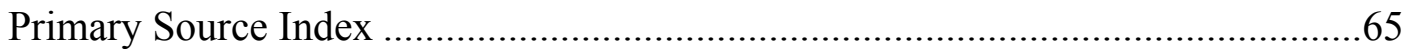

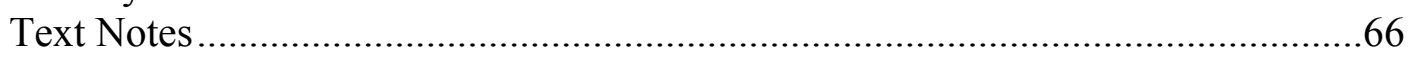




\section{INTRODUCTION}

The whole edifice of the Enlightenment, beginning with Descarte's work Discourse on Method published in 1637, was geared towards a recognition of the power of human knowledge over dogmatic faith and authority. It was thought that the real history of humanity was a struggle for self-knowledge which would bring humanity to a state of enlightenment. The Enlightenment was an emancipation of the human mind from a state of dogmatic ignorance, which in part was fueled by the Protestant Reformation against the Catholic Church (beginning with Luther's Ninety-Five Theses published in 1517 and concluding with the Peace of Westphalia in 1648). The Enlightenment movement marks a shift in intellectual ideas previously based on faith, tradition and authority, towards an emphasis on the individual and the power of human Reason.

Kant's Critical Project was to explore the limits and conditions of human Reason. The Critical Project consisted of the Three Critiques; Critique of Pure Reason (A-ed. 1781 and B-ed. 1787), Critique of Practical Reason (1788) and Critique of Judgment (1790). In general, Kant's aim was essentially to bring together Reason and experience (a project which, on Hegel's account fails, and which Hegel thought he had achieved in some sense).The current research is mainly an exegesis of the second part of the Third Critique but will also analyze part of the First Critique to supplement where necessary.

In the Critique of Pure Reason, the section "Appendix to the Transcendental Dialectic" we will look at the second part "On the Regulative Use of the Ideas of Pure Reason," which is where Kant addresses the regulative function of the idea of systematicity for scientific inquiry. Here he establishes Reason's interest in securing 
systematic unity of empirical knowledge which would bring such knowledge to completion. Hegel's critique is targeted at Kant's assignment of systematicity as a regulative function of Reason instead of a constitutive function of Reason. Hegel argues, that if Kant had given systematicity constitutive applicability, then it would be capable of completing the task of unifying Reason with experience.

The Critique of Judgment is divided into two parts; The Critique of Aesthetic Judgment and The Critique of Teleological Judgment. The so-called First Introduction was not published in Kant's lifetime, but Kant wrote a replacement for publication (referred to as the Published Introduction). This paper looks at sections IV and V of the Published Introduction where Kant establishes that the principle of teleology is nonempirical and a priori (a priori in regulative judgment). The second part of the Kantian analysis will focus on Sections 68 and $§ 74-\S 76$ of the second half of the Third Critique; Critique of Teleological Judgment. These sections deal with the concept of teleology as a principle of reflective judgment which aims at regulating empirical inquiry. Kant asserts that the organic must be explained "as if" it were constituted as teleological, even though such a theological principle is impossible to verify by experience. Hegel is critical of the regulative constraints Kant put on teleology as well as its heuristic basis. The organic concept, constitutively understood, would be able to unify Reason and nature, and possibly salvage a theological interpretation of reality, something that was being threatened due to new Enlightenment ideas. Hegel's project is often seen as the last attempt to salvage a theological understanding of nature in the post-enlightenment world.

Hegel's relation to Kant's critical philosophy is of primordial importance for an understanding of Hegel's position. Hegel's concept of nature in as early as his works 
Difference (1801) and Faith and Knowledge (1802), and later in the Phenomenology (1807) and the Philosophy of Nature (1817), he undertakes the task of continuing and completing Kant's Critical Philosophy by connecting Reason and Nature by his constitutive theory of teleology. In a letter Hegel wrote to Schelling (16 April, 1975) he spoke about his vision; "From the Kantian system and its highest completion I expect a revolution in Germany."

The idea of the intuitive intellect proposed by Kant is pervasive throughout Hegel's system, and as I will argue, is the cornerstone for his development of a teleological understanding of nature. Hegel's critical appropriation of the Kantian intuitive intellect started in his early works Difference and Faith and Knowledge. In these works, he began his reformulation of Kant's concept of an intuitive intellect by making it into a constitutive concept instead of a regulative idea. Kant's denial that our understanding is intuitive is based on his view that there are two sources of knowledge. Commonly referred to in the literature as the two-source hypothesis, according to Hegel, limits human cognitive capacities and leads to the inability to ultimately connect Reason's concept of teleology with Nature. Hegel's alternative, which posits an identity between Reason's concept of teleology and Nature developed as a direct consequence of his adoption of Kantian intuitive intellect as a constitutive concept.

In the Phenomenology, Hegel tells the history of consciousness beginning with sense perception and culminating in absolute knowledge. This research will focus on the section "Reason: Observation of Nature," in which Hegel states his critique of empirical science. He regards empiricism as inadequate because it is limited to a contingent explanation of nature. In this section, he also develops his metaphor of the Instinct of 
Reason which demands that we exceed this stage of epistemology in order to reach a logical conception of nature. Hegel's constitutive concept of teleology is implicit in this section of the Phenomenology, but unfortunately, is not treated systematically. The current research will attempt to reformulate his constitutive theory of teleology in contrast to Kant's regulative theory of teleology based on the scattered remarks in the Phenomenology.

Due to the fact that teleology is treated unsystematically requires us to look at some other of Hegel's writings. The Introduction to Hegel's Philosophy of Nature gives a good general insight into the overall vision of Hegel's project of rationalizing nature. In the Introduction, Hegel clarifies the a priori status of the "inner idea" or "purposiveness" (i.e., the logical structure of reality) which determines nature out of its own immanent necessity, and hence, marks the necessary transition from Reason (logic) to Nature. I will contrast the a priori status of the idea of inner purposiveness with Kant's regulative $a$ priori principle of purposiveness. I will suggest, based on this text, that Hegel viewed Kant's a priori concept of teleology not as a true a priori concept because it was rooted in reflective judgment, and hence, unable to do the "heavy lifting" that Hegel's true $a$ priori concept of teleology was able to do. Hegel's a priori concept of teleology guaranteed that Reason extended into nature and would be available to us through empirical investigation.

\section{General Statement of Problem}

Hegel and Kant agree that there is a contradiction between Reason's requirement for necessity in theoretical science and contingency in the way we conceive of nature's 
particulars. The problem is that in experience we find that nature exhibits contingencies that do not seem to conform to our rational framework. Formulating a teleological explanation of nature allows for contingency in nature to be accounted for. The difference is that for Kant a theological conception of nature is used as an explanatory principle, but God has no place in natural science, while for Hegel a theological understanding of nature is not only a useful explanatory principle, but resolves the remainder of contingency in the natural scientific explanation of nature. In the first case, the concept of teleology does not extend beyond subjective conditions, and therefore, does not explain the elimination of contingency in nature, but is used merely as a guide to regulate empirical knowledge. Hegel envisioned a scientific conception of teleology, which would give God a place in natural scientific inquiry. Hegel is oftentimes considered the last true metaphysical defense for a theological conception of nature. He believed that the theory of teleology would allow us to go beyond the limitations of empirical science and could therefore serve as a more powerful explanatory principle than Kant had originally considered it to be. Hegel's objective principle of teleology allows us to conceive of nature as containing an inherent logical necessity.

Hegel's critique of Kant's concept of teleology is that it is a superficial resolution to the problem of contingency because it does not address contingency in nature, but merely contingency in empirical laws. According to Kant, judgment produces the law of teleology in order to systematize empirical laws, and thereby generate regulative necessity, but the problem is that it leaves the fundamental problem of contingency in nature in place. For Hegel, the law of teleology would have more explanatory power if it 
were not only regulating empirical concepts, but unifying nature itself (i.e., generating constitutive necessity).

Hegel's argument is that Reason demands more than regulative (subjective) necessity of empirical concepts. Reason requires more than regulative or subjective necessity because it is instinctively driven beyond the limits of empirical knowledge (i.e., contingency of sensible particulars). In the Phenomenology he argues that the phenomenology of consciousness begins with empirical inquiry, which is the most immediate form of knowledge, but is then ultimately driven beyond contingent sense perceptions to logical concepts. The Instinct of Reason (Vernunftinstinkt) is Hegel's metaphorical (and theological) proxy for Reason/God which can ultimately eliminate contingency and bring nature into conformity with the logical Idea (the will of God eventually manifesting itself in reality). To continue the metaphor, the instinct (or cunning) consists in Reason's ability to conform so that nature can ultimately be an expression of Reason. Reason is expressed in nature, in other words, it is constitutive of the object (Reason determines nature). Teleology for Hegel is therefore a concept of Reason which is expressed in nature itself.

Hegel is largely indebted to Kant's conception of teleology in the Critique of Judgment, but he supersedes Kant's subjective standpoint. Hegel remedies the contradiction of necessity and contingency with the concept of an objective principle of teleology which allows no gap between nature and Reason. For Hegel, the contradiction between contingency and necessity can be overcome when we grant human intellect some of the powers of the intuitive intellect first envisioned by Kant. Kant understood God to be the only possible being with an intuitive intellect, and so limited the finite 
intellect to discursive understanding for which there is an ineliminable contingency between nature and Reason, and for the way we perceive sensible particulars. For the finite intellect, which intuits nature by means of sense perception, particulars seem to be isolated, and indifferent to each other, with no necessary connection. Hegel argues that Kant should have awarded human beings some of the powers of an intuitive intellect, for which these two types of contingency are eliminated. For an intuitive intellect there would be no contingency between Reason's concepts and nature's products, nor for the way we perceive sensible particulars. The elimination of these two contingencies is characteristic of Hegelian teleology. In Hegelian teleology, there is no gap (contingency) between Reason's concept of teleology and nature. There is an identity between the concept and the object since nature is an expression of teleology. Also, there is no contingency between particulars themselves. Under the teleological explanation, particulars are necessary, that is, they are explained as a necessary part of the whole organic concept.

\section{Division of Chapters}

Chapter One describes in what sense Kant limits human understanding to the discursive mode of thinking. For the discursive intellect there is an ineliminable contingency between Reason's concepts and nature's products since they are considered two independent sources of knowledge, and there is also an ineliminable contingency in the way particulars are presented to the discursive intellect because of its reliance on those independently given sensible intuitions. Kant denies that human beings have the powers associated with an intuitive intellect in which these two types of contingency would be 
eliminated. Hegel's critique of the two types of contingency in Kant's concept of teleology is based on this fundamental limitation Kant places on human understanding. If human understanding were granted some of the powers of the intuitive intellect, then the contingency between Reason's concepts and nature's products, as well as contingency of particulars would be eliminated.

Chapter Two concerns Hegel's critique of the first type of contingency in Kantian teleology; contingency between Reason's concept of teleology and nature. For Kant, the concept of teleology is subjective and is contingently related to objective nature. The subject-object distinction can be seen when we understand that for Kant the referent of the law of teleology is not nature at all, but rather, the cognitive faculty of the Understanding. Since the subjective law of teleology is applied to concepts of the Understanding, and is wholly independent and contingently related to nature, the principle cannot venture to make any claims about the object. It is therefore, according to Hegel, merely making an empty claim since it is not balanced (verifiable) by anything objective. This implies, most importantly, that Kantian teleology is a non-empirical concept, and hence, justification of the theory is impossible to determine (not verifiable by experience).

In Hegel's alternative, the relationship between the concept of teleology and nature is not contingent because the concept is not independent from nature, but actually extends into nature. The referent of the law of teleology is nature itself, as opposed to a representation (Vorstellung) of nature within cognition. Teleology is not a detached and unrelated concept external to the nature of things, but concerns the constitution of objects themselves. Hegel's law of teleology is objective and empirical, and hence, verifiable by 
experience. By making teleology an empirical concept, Hegel is able to develop a theological conception of nature that is scientific in the sense that it is based on observation and experience. Hegelian teleology ultimately serves as an apology for a theological conception of nature. What differentiates his theory from other theological conceptions of nature is that it does not require recourse to a religious ideology which is based on unobservable phenomenon. The organic in nature is the proof of teleology (God is immanent in nature as opposed to transcendent). Hegel's development of a scientific teleology can possibly resuscitate the theological understanding of nature in an age where science dominates.

Chapters Three and Four concern Hegel's critique of the second type of contingency in Kantian teleology; contingency of particulars. Chapter Three describes Kant's argument for why Reason's concept of teleology requires mere regulative or subjective necessity rather than constitutive or objective necessity. Kant designates the goal of teleology to be the elimination of contingency in empirical laws not in nature's sensible particulars. Thus, Kant assigns the principle of teleology to reflective judgment to complete this task and not determinative judgment. If it were assigned to determinative judgment, it could be capable of postulating the elimination of contingency in particularity. Regulative status of this principle means that it is utilized as a heuristic device to regulate inquiry and systematize empirical knowledge, but it cannot further determine the object (i.e., it cannot generate constitutive necessity). Furthermore, it cannot be given the status of a true a priori principle because of its origin in reflective judgment. Since it is a quasi-a priori principle rooted in reflective judgment, objective reality of the principle is impossible to determine and is thereby limited to subjective 
theorizing. Thus, unity in our concept of nature, not unity in nature itself, is the final outcome of employing this regulative principle.

Chapter Four describes Hegel's argument for why Kant's solution to the problem of contingency is a superficial one since Kant regards the concept of teleology as merely a regulative principle (heuristic device) to guide inquiry. Kant's regulative principle merely eliminates the contingency between laws of nature by creating systematicity and unity among them, but for Hegel, this makes Kant's principle of teleology un-scientific since it is non-empirical (i.e., it does not address actual contingency in nature). Hegel regards Kantian teleology as purely subjective and his conception of the laws of nature as purely psychologistic. Consequently, Hegel develops a concept of teleology out of the need to reach knowledge of necessity in nature's products. Actual contingency in nature's products can only be overcome by postulating a constitutive principle of teleology which conceives of nature's products as necessarily related (objective necessity), not just psychological laws of nature necessarily related (subjective necessity).

In the final two chapters I indicate the importance of Hegel's reformulation of Kant's regulative principle into a constitutive principle, specifically, because it makes teleology scientific. When teleology is employed as a scientific theory, it serves as a powerful explanatory tool which could explain away the contingencies of nature not by recourse to religious dogma, but based on the scientific method of observation. Ultimately, Hegelian teleology serves as a defense for a theological understanding of nature which places God back into scientific inquiry. For Hegel, a theological explanation of nature is not only useful in natural science, but it is also necessary because it is a comprehensive theory which allows us to explain away contingencies remaining in the 
empirical explanation of nature. Hegel's defense, however, is based on a highly problematic idea; the Instinct of Reason. The instinct of human reason to go beyond the contingencies remaining in the empirical explanation is not enough, in my view, to guarantee the necessary transition in epistemology from empiricism to teleology. 


\section{CHAPTER I:}

\section{TWO TYPES OF CONTINGENCY ASSOCIATED WITH THE DISCURSIVE INTELLECT}

Were our understanding intuitive...concepts (which concern merely the possibility of an object) and sensible intuitions (which give us something without yet allowing it to be known as object) would both fall away [wegfallen]. ${ }^{2}$

Hegel believes that Kant should have awarded the human intellect some of the powers of the intuitive intellect instead of the limited powers of the discursive intellect whose concepts are merely regulative. Considering the concept of teleology as regulative and not constitutive limits it to the conceptual sphere, which is completely independent from reality, and so is not capable of considering nature itself as purposeful. The discursive intellect distinguishes between concepts (which concern the possibility of the object) and sensible intuitions (which concern the actuality of the object). From the standpoint of the discursive intellect, teleology is merely conceptual so is therefore limited to mere possibility. If our understanding were intuitive, however, there would be no distinction between concepts and sensible intuitions, and thus, teleology would not be a mere concept concerning the possibility of unity, but would concern actual unity of nature.

Furthermore, if the concept of teleology were understood from the point of view of an intuitive intellect, the two types of contingency associated with discursive thinking, contingency of particulars, and contingency between concepts and intuitions, would "fall away." Hegel's critique of contingency in Kant's concept of teleology is based on the fact that Kant did not award the human intellect the powers of the intuitive intellect to formulate a constitutive concept of teleology, which would have eliminated contingency 
in nature, not just in the idea of nature. Kant did not award human beings the power of an intuitive understanding because he believed only God could possess such powers. Hegel, on the other hand, pushed the boundaries of the finite intellect. Hegel blurred the distinction between Divine and human Reason by extending the powers of the finite intellect to intuit nature by means of necessary concepts as an intuitive understanding would.

\section{Two Types of Contingency}

Kant attributes human understanding to discursive thinking. There are two types of contingency associated with the discursive intellect. These contingencies arise from the fact that for the discursive intellect there are two sources of knowledge; the faculty of the Understanding which provides concepts, and the object which provides sensible intuitions. Since finite understanding is dependent on sensible intuitions in order to have knowledge of nature, "the variety of ways in which [the given particulars] may come before our perception is contingent." ${ }^{33}$ Furthermore, due to the subject-object distinction in finite understanding there is also contingency between our concepts and given sensible

particulars. ${ }^{4}$ Hegel concurs, that for the discursive understanding, these two types of contingency exist; contingency of particulars, and contingency between concepts and intuitions. Hegel writes in regards to the discursive intellect, "Concepts remain contingent with respect to nature just as nature does with respect to the concepts."

The peculiarity of the finite understanding is that it requires a synthesis between these two heterogeneous faculties (concepts and sensible intuitions) in order to have knowledge of nature. The finite intellect begins by proceeding from the "analytic 
universal" $^{\prime 6}$ to the particular (i.e., from concepts to the empirical intuition that is given). The discursive understanding is responsible for supplying concepts (analytic universals), but these concepts by themselves are not adequate to determine the existence of objects, that is, they do not produce objects. Therefore, they are dependent on independently given sensible intuitions. Therefore, in order to have knowledge of particulars, sensible intuitions that are independently given must be synthesized with concepts.

On the contrary, for the intuitive intellect there is no requirement for synthesis because there are not two distinct sources of knowledge. There is only one source of knowledge because there is only one object. For the intuitive intellect, there is no contingency between nature and the intellect because there is no distinction between them. Contingency "falls away" because concepts and intuitions are one. Intuitions of the intuitive intellect are not dependent on independently given sensible intuitions. The intuitive intellect proceeds directly from the "synthetic universal" (the intuition of the whole as a whole). ${ }^{8}$ An intuitive intellect would presumably enjoy a "complete spontaneity [as opposed to receptivity] of intuition" since particulars are products of its intuiting. ${ }^{9}$ Out of its own concepts (or synthetic universals) particulars are simultaneously generated.

If our understanding were intuitive, then the concept of teleology would be expressed in nature (since concepts simultaneously generate intuitions), and hence, particulars in nature could be explained as a necessary feature of a much more comprehensive whole. In other words, when we consider nature in terms of purposiveness, contingency would no longer be a feature of nature's products since all particulars would be conceived as part of the necessary whole. All the aspects of nature 
that do not seem to conform to our rational framework would become essential, or purposeful, parts.

\section{Possibility and Actuality}

Since concepts and sensible intuitions are distinct for the discursive intellect, the finite mind also distinguishes between the possibility and the actuality of things (concepts concern possibility, and sensible intuitions concern actuality). ${ }^{10}$ For the finite mind, concepts by themselves concern merely the possibility of an object because its objects are not necessarily actual. Theories regarding the possibility of an object are merely theoretical constructs in relation to our cognitive powers, but theories regarding the actuality of the object are theories about the thing itself [an sich selbst] in relation to sensible intuitions. ${ }^{11}$ Kant's principle of teleology is purely conceptual, and is not synthesized with sensible intuitions, so therefore, teleology is restricted to the sphere of possibility. This means that teleological judgments are not propositions about the thing itself, i.e., they do not concern the actual determination of the object. Teleology remains entirely independent (i.e. external) from nature. Since no synthesizing activity takes place, (since teleology is not balanced by an objective world), unity of nature is merely thought, not actually known.

For the intuitive intellect, however, since concepts and sensible intuitions are one,

possibility and actuality are also one. ${ }^{12}$ The objects of the intuitive intellect are not merely possible, they are necessarily actual. For the intuitive intellect there is no need for concepts (i.e. theories limited to mere possibility) concerning nature because it generates 
nature from mere intuition (i.e., self-determination). All concepts/theories are necessarily actual for this intellect because all objects that it thinks necessarily exist.

In order to conceive of nature as purposeful, Kant appeals to the idea of God or an intuitive intellect. But this appeal to an intuitive intellect is only used as a guide for research, and therefore is a theory concerning mere possibility of unity in the object. ${ }^{13}$ Teleology is a transcendental maxim imposed by Judgment, an appeal to a cause outside of nature in a supersensible intelligent being to guide theoretical inquiry. However, Kant considers the supersensible substrate to be beyond sensibility and therefore beyond human understanding, so it can only allow us to postulate systematic unity as a possible object of experience (not a real or actual object). That is, when we think the object under the subjective principle of teleology, we are not making any assertions about the unity of the object, only about the possibility of unity. Hegel posits teleology as not merely existing within another understanding totally transcendent and ungraspable (God or a supersensible being), but rather, existing as a thing [Ding], immanent in nature. God's Reason is immanent in nature, within organic life, which essentially means that Reason exits in (or as) nature. In Hegel's words, "the concept of purpose is not existing elsewhere in some intellect but exists here as a thing." 14

Hegel argues that we should consider teleology from the point of view of an intuitive intellect and not distinguish between possibility and actuality. As a result, the concept of teleology would be a theory about the determination of the actual object, not just about the possibility of the object. Hegel's concept of teleology implies the idea of an intuitive intellect not just as a guide for research, but as feature of human cognition. ${ }^{15}$ Hegel adopts Kant's idea of an intuitive intellect in his development of the concept of 
teleology since he granted powers of an intuitive intellect to human cognition. ${ }^{16}$ Hegel assimilates teleological judging with the powers of the intuitive intellect because it is capable of eliminating contingency in nature, not just in the idea of nature.

Kant was closest to Hegel's theory of teleology when he envisioned the elimination of contingency in the intuitive intellect. Kant postulated the elimination of contingency in nature; he wrote that for the intuitive intellect there is no contingency between "the way natures products in terms of particular laws harmonize with [it]. ${ }^{17}$ But instead of granting human powers the ability to view nature in this way, he limited human powers to discursive thinking which proceeds from parts to whole, and not from whole to parts. Kant envisioned an external principle which determined the object (i.e. external purposiveness) but this external determination only concerned the possibility of the object, and hence, could not give us insight into reality.

If the principle of inner purposiveness had been adhered to and developed in its scientific application, it would have brought about a completely different, much higher way of envisioning this purposiveness. ${ }^{18}$

Hegel is arguing here that if Kant had envisioned teleology as part of the nature of things (internal purposiveness) instead of distinct from nature and imposed on it by external means (external purposiveness), it could have counted as a scientific theory. In the quote above, Hegel is contending that if we were to count teleology as a scientific theory, that is, if we were to count teleology as a concept which is internal to nature and determines nature, we would be able to conceive of nature's products as necessarily related. 


\section{CHAPTER II:}

\section{CONTINGENCY BETWEEN REASON AND NATURE}

The first aspect of Hegel's critique of Kant's law of teleology is focused on the contingency it establishes between Reason's concept of teleology and nature's products. The contingent relationship between teleology and nature arises due to the fact that Kant limits human intellect to a discursive mode of understanding, which makes a distinction between concepts and nature. It follows from this consideration, that teleology is a subjective concept, which merely unifies nature within cognition, and is contingently related to objective nature. In fact, the subjective law of teleology does not pertain to the determination of the object at all, but to a second object, i.e., a representation of nature within cognition.

Hegel is attracted by the powers given to the intuitive intellect which are capable of eliminating contingency between concepts and nature. From the standpoint of an intuitive intellect, the concept of teleology would be actual (i.e. determined) in nature. With Kant's idea of an intuitive intellect in mind, Hegel formulates an objective concept of teleology which postulates unity in nature itself, not just within the subject. The concept of teleology is objective since it is not transcendent, but rather immanent in nature. It is determined in nature out of Reason's own concept (self-determination). The force of the objective law of teleology is that contingency between the concept of teleology and nature would be eliminated, and consequentially, the theory would concern the determination of the first object (nature itself). 
The current chapter will firstly explore excerpts from Kant's Third Critique in order to reconstruct his subjective law of teleology, and secondly, we will explore excerpts from Hegel's Phenomenology in order to demonstrate Hegel's alternative to subjective teleology.

\section{Observing Reason}

Kant's principle of teleology has the same limitations of the epistemological stage of "Observing Reason/Consciousness." Just as Kant makes the distinction between the subjective law of teleology and nature, the observing consciousness makes a distinction between Reason's concepts and nature. Consequently, at this stage of knowledge of nature, it seems as if the concept of teleology were part of subjective consciousness and not a reflection of the nature of things. Hegel claims that Observing Reason makes the error of looking for teleology within itself instead of acknowledging its existence in nature. Hegel's fundamental claim is that Reason is the essence of nature. By this he means that Reason's concept of teleology is an expression of nature; concept and object are one. At the epistemological stage of observation, Reason is not yet aware of this identity. Despite Reason being unaware of the conformity of its concept with nature at the stage of observation (since concepts and nature seem to be opposed), Reason instinctually knows they are one, so it seeks in nature the expression of itself- it seeks unity. The quote below is characteristic of what Hegel describes as the Instinct of Reason which is his metaphorical proxy for Reason/God (more on the Instinct of Reason in the following chapters). Reason or God knows that what it seeks in nature is itself, since nature is Reason. 
However much it [Observing Reason] were likewise to know reason to be the essence of things and the essence of itself, still it would to an even greater degree descend into its own depths and look for reason there rather than in things. If it were to find reason there, it would at that point once again turn around and be directed outwards toward actuality in order to see its own sensuous expression in actuality. ${ }^{19}$

When Hegel describes the activity of consciousness as "descending into its own depths and looking for Reason there rather than in things," Hegel is expressing his dissatisfaction for looking inward into [subjective] consciousness for the principle of teleology rather than finding it expressed in [objective] nature. In order for teleology to be an objective law, it must not only conform to nature, but also be an expression of nature. Hegel articulates it thusly: “...the artificial system should be in accordance [in conformity] with the system of nature itself and merely express it." 20

The importance of this excerpt is that it demonstrates that in Hegel's view teleology is an objective, empirical concept. The concept may appear to be within the subject, but Reason is driven outward towards actuality to discover that it is not merely a concept, but a thing. This means that it is something that is actually observed in nature; Reason has its sensuous expression in nature as organic life. Since teleology is empirically knowable, this means that it is verifiable by the same method used to verify scientific theories; observation.

\section{Kant's Subjective Law of Teleology}

In Part II of the Critique of Judgment, "Critique of Teleological Judgment," particularly in $§ 74$, "The Reason Why it is Impossible to Treat the Concept of Technic of Nature Dogmatically is that a Natural Purpose is Inexplicable," Kant argues against the 
possibility for proving objective teleology since it is not an empirical concept. In order for the law of teleology to be given objective reality, an object conforming to it must be possible (justification must be possible). Kant makes the distinction between dogmatic and critical concepts of Reason. In order for a concept to be dogmatic, its objective reality must be verifiable by experience, in other words, it must be provable that an object conforming to the concept is possible in order that we can formulate laws and subsume natural objects under them. However, Kant does not attribute teleology to dogmatic concepts because it is not verifiable by experience. Instead, Kant attributes teleology to the category of critical concepts, since it is applied only in relation to the subject's cognitive powers.

We treat a concept merely critically if we consider it in relation to our cognitive power, and hence in relation to the subjective conditions under which we think it, without venturing to decide anything about its object. ${ }^{21}$

Teleology is a rational principle used to judge the object, but there is no way of establishing (dogmatically) that it has objective reality. Kant argues that teleological judgments are neither affirmable nor deniable by observation or experience. Consequentially, objective teleological claims only render problematic judgments about the object because there is no guarantee that an object conforming to it is possible. ${ }^{22}$

The Kantian attitude towards teleology is, hence, a skeptical one. Proving the objective reality of the theory is suspended indefinitely since the question cannot even be asked. We cannot tell by observation whether nature requires a special kind of causality such as purposiveness in the production of objects. The concept is an objectively empty concept (conceptus ratiocinans) impossible to prove by Reason and merely used as a guide to our reasoning. Since it is not a rational concept confirmable by Reason 
(conceptus ratiocinatus) it cannot be used as a basis for cognition, nor as a principle in natural science.

Interestingly enough, Kant admits that the concept may seem to have objective reality, since the concept of natural purpose is empirically conditioned, that is, it is a concept that is possible only under certain conditions given in experience. ${ }^{23}$ Nonetheless, teleological judgments are not empirical or synthetic judgments, ${ }^{24}$ meaning they are not taken from experience, but are a priori judgments (a priori based in reflective judgment) giving them only indeterminate validity- meaning justification is impossible. ${ }^{25} \mathrm{We}$ presuppose this unifying principle and conduct scientific inquiry as if it were objective, otherwise, to employ such a principle without assuming it could in theory conform to nature, would be absurd. ${ }^{26}$ Kant writes, then "reason would run counter to its own vocation, proposing as its aim an idea quite inconsistent with the constitution of nature. ${ }^{27}$ Teleology is assumed to be necessarily inherent in the objects, but conformity of this concept with the object is impossible to verify.

The principle of teleology is employed as a basis for subjective cognition only, and has no place in natural science. So why employ this principle at all if it is not useful in natural science? Kant makes the distinction between suppositio relativa and suppositio absoluta $^{28}$ which could give us a clue. Teleology is a supposition relative to the need of Reason, for systematicity of empirical knowledge, but not absolute, as making a claim about the existence of such an idea. Only the latter would result in an objective [dogmatic] assertion. Kant is explicit on the point that there is "nothing that can assure us that the concept has objective reality." ${ }^{29}$ The principle enables human Reason to connect particular experiences, and in so doing, grasp nature as a whole system. Otherwise, 
without employing this principle our experience of nature would be a heap of contingent objects without any order, and consequentially, we would have no coherent experience of nature at all.

Transcendental principles do provide us with a good basis for assuming that nature in its particular laws is subjectively purposive for the ability of human judgment to take [it] in, making it possible to connect the particular experiences to [form] a system of nature. ${ }^{30}$

Kant limits teleological judgments to subjective assertions which are utilized relative to the need of Reason for systematicity in order to bring natures appearances under rules. This allows us to have subjective knowledge of an order of nature but not knowledge of an objective order of nature. In so doing, we are able to have a coherent experience of the natural world.

\section{Referent of Teleology: The Understanding}

According to Kant, the referent of teleology is not nature, but nature within cognition. This implies that unity of nature is restricted to the subject, with no reference to unity of the object. In the Critique of Pure Reason, "The Final Purpose of the Natural Dialectic of Human Reason," Kant draws the distinction between something given to Reason as an object absolutely and an object in the idea. ${ }^{31}$ An absolute object is one in which our concepts are employed to determine the object. An object in the idea is one in which we represent to ourselves, and therefore, does not give us insight into objective reality. The referent of teleology is not the absolute object (i.e. nature), but rather, an object in the idea. ${ }^{32}$ The idea of teleology makes reference to an object in the idea only and not an object absolutely since it "does not directly relate to, or determine, any object 
corresponding to it." ${ }^{, 33}$ Given that the referent of teleology is an object in the idea only, it is considered a symbolic representation (Vorstellung) of nature. Consequentially, for Reason there is no concrete object, the only object of Reason is the representation of a unified nature within the Understanding.

Reason has, therefore, as its sole object, the understanding and its effective application. Just as the understanding unifies the manifold in the object by means of concepts, so reason unifies the manifold of concepts by means of ideas. ${ }^{34}$

The faculty of the Understanding is immediately related to sensibility and orders the manifold of the senses (i.e., the appearances of nature). In turn, Reason is immediately related to the Understanding and is the additional rule employed by Judgment to order concepts of the Understanding. Reason's role is to unify the concepts of the Understanding, but it does not unify sensible intuitions. Reason, therefore, is never in an immediate relation to nature, only to concepts of the Understanding, which makes the relationship contingent.

\section{Objective Contingency of Teleology}

Since the object of teleology is not nature, but nature within cognition, teleology is considered to be a concept that is independent and contingently related to nature's products. Unlike the relationship between the categories and nature which are co-

dependent, ${ }^{35}$ teleology is a heautonomous ${ }^{36}$ principle which means that it is independent from the object. Judgment applies the principle only to itself (i.e., the subject) in order to systematize nature's appearances, but it is not balanced by any object (like in the case of the categories). The concept unifies nature within the subject but is entirely free standing and unrelated to the object. 
For understanding acknowledges at the same time that this harmony is contingent objectively, and only judgment attributes it to nature as a transcendental purposiveness (in relation to the subject's cognitive power). ${ }^{37}$

The harmony of nature is assumed by the Understanding only in relation to subjective cognition, but harmony of nature is contingent objectively. Judgment attributes the teleological conception of nature to a transcendental being, which implies another understanding that is not ours (i.e. God), and so, uses the supersensible as a basis for comparison. The subjective principle allows us to compare the transcendental principle of teleology with the object by analogy. ${ }^{38}$ Hegel argues, however, that when we compare nature by analogy with a supersensible substrate, this does not allow us to explain nature at all because it is independent from nature. Hegel argues that analogy is not a sufficient criterion for justification of empirical truth because it does not permit us to draw inferences, at best, it can yield probability, not true objectivity. ${ }^{39}$ If Kant considered the principle to be immanent in nature's products then it could permit us to draw an inference about the constitution of the object.

\section{Hegel's Critique of Subjective Teleology}

In the Phenomenology, in the chapter "Reason: Observing Reason," Hegel begins to formulate a theory for the objective law of teleology based on the idea of the intuitive intellect in which there is no contingency between concepts and nature. Hegel formulates his theory of internal teleology in reaction to Kant's external teleology in which the concept of purpose and thinghood remain opposed and unrelated terms. Hegel finds external teleology to be problematic since it remains entirely disconnected from 
thinghood. Theoretical unity of nature (i.e., external teleology) generated by the subject remains an abstraction, that is, a suppositional activity lacking determination.

Hegel's critique of Kant's principle of teleology concerns Kant's recourse to subjective maxims, which are used to entertain mere possibilities, instead of making teleology an objective principle which describes actuality. Kant's principle of Reason does not count as an explanation about the construction of objects themselves. Since Kant establishes human intellect as discursive, which posits a contingent relationship between concepts and nature's products, teleology and nature remain external unrelated terms, and hence, teleology cannot yield objectivity, necessity or universality.

Hegel argues that if teleology remains a theoretical construct and subjective addition, then it cannot serve as an adequate ground for natural science. Furthermore, in order to count as a scientific theory (i.e. an objective, universal and necessary law) it cannot be an external form and subjective addition but must be a determinate concept in order to count as a proposition about the thing-itself. ${ }^{40}$ Hegel considers teleology to be a theory of the universal system of nature, a universal that is not just an abstraction, but that is also determined. ${ }^{41}$ The theory of teleology would have no force (it would not be an adequate explanation of nature) if we did not assume that nature itself contained unity. He argues that we must go beyond the abstraction in order to prove that teleology exists in nature. Proof must be taken from observation of nature in order for it to be a scientific theory, otherwise, if it were not scientific, it would not be useful at all. In Hegel's words, "what does not appear, is for consciousness nothing at all.",

At the same time, however, this portrayal of nature remains merely teleological [nur teleologisch], meaning valid only as a maxim of our limited discursive thinking human understanding, in whose general concepts the particular 
appearances of nature are not contained. From this human point of view nothing about the reality of nature is supposed to be said; this standpoint remains through and through something subjective and nature a pure objective, something merely thought. $^{43}$

In this quote from the Difference Essay, Hegel is attacking Kant for maintaining the subject-object distinction. Kant limited human thought to discursive thinking, so the concept of teleology remains a subjective construct, and nature an objective thing. In so doing, the concept of teleology is not capable of explaining the particular appearances of nature. Instead of limiting teleology to discursive thinking as Kant had by deriving unity from a mere idea determined by external purposes (from the maxims of human reason), Hegel removed the limits Kant placed on human understanding so that the concept of teleology could be conceived as part of the construction of nature. The concept of teleology considered as a scientific theory means that it explains the determination of objects themselves, including nature's appearances.

Teleology for Hegel is not a transcendental principle which extends beyond our understanding, but rather, is immanent and observable in nature's products. The subjectobject distinction is thereby eliminated in Hegel's understanding of teleology. Teleology counts as an absolute judgment, that is, a proposition about the thing-itself because the concept and the intuition are one. Furthermore, Hegel does not consider Kant's principle to be a law at all because its referent is not objective reality, but instead, something wholly separate from reality. The law of teleology must be objective, that is, discoverable in nature in order to be considered a law and to be scientific. Hegel considers Kant's concept of teleology to be a limited insight since the theory does not go beyond the subject, that is, it does not extend beyond the subject into nature. 


\section{Objective Law of Teleology}

Hegel views the concept of teleology from the point of view of an intuitive understanding in the sense that teleology is both conceptual and sensuous. The concepts of teleology and nature do not have a separate and isolated content matter; their form differs, but their content is the same. The form of teleology takes the shape of a concept and also as an object in nature. In other words, the content of the theory is expressed as nature because concept and object are one and the same.

Hegel describes the objective law of teleology as a "non-sensuous sensuosity" (unsinnliches Sinnliches). ${ }^{44}$ The law exhibits itself in nature as two related moments: (1) sensuous, empirical being (empirical and particular), and (2) sublation of sensuous being (necessary and universal). ${ }^{45}$ The concept of teleology first appears from the point of view of observation as empirical and particular being. He writes, as it first appears to observation the concept turns out to "exist in the mode of thinghood and sensuous being. ${ }^{, 46}$ Hegel argues that the law of teleology must have sensuous existence and be available to experience, that is, available for observation in order to count as an objective and scientific law. "It [the organic as purpose] is phenomenally and sensuously present that it is a purpose in itself and is thus observed., 47

As the law first appears, it exhibits itself impurely, as enveloped in individual sensuous being, and the concept which constitutes its nature exhibits itself as sunken in empirical material. ${ }^{48}$

The sensuous stage of the law has the same limits as the point of view of a discursive understanding which posits empirical particulars as contingently related. Contingency of particulars is seen as the most uncertain form of knowledge of nature. When objects are viewed as isolated things which are contingently related (i.e. difference), nature is not yet 
conceived as a unified whole, nature is viewed as contingent. It only partially exhibits the concept of teleology. Hegel reiterates, "Isolated things have no actuality." ${ }^{49}$ In this phase of knowledge of nature, it is not yet understood how the parts relate to the whole.

As a result of contingency of particulars, consciousness is forced to move to the second stage, the universal aspect of the law whereby the isolated objects are seen as necessarily related (i.e. identity). Consciousness moves to the point of view of the intuitive understanding and intuits nature as a whole instead of an aggregate of unrelated parts. Consciousness shifts its point of view away from the contingency of particularity, and instead, finds the necessity of the concept of teleology expressed as an organic whole whereby purposiveness is saturated in every part of nature.

The inner significance of this research is that it finds the pure conditions of the law, and even if the consciousness expressing this should think that by doing so it is saying something different, it in fact is saying nothing else than that it is supposed to elevate the law entirely into the concept and to do away with all the link its moments have to determinate being. ${ }^{50}$

Consciousness instinctively elevates the sensuous being of the law into a concept in order to make particulars a comprehensible system (i.e., to eliminate contingency remaining in observation). Hegel makes a parallel argument in the previous section on "SenseCertainty." He argues that when we perceive things by means of sensibility, consciousness is perceiving things in their immediate state as individual properties with no relationship to one another. Things are a series of "this"" "here's" or "now's" with no connection. But he continues, that things do not have truth at this stage of thinking. Particulars by themselves are the poorest form of truth because they are detached, unrelated things. ${ }^{51}$ Consciousness instinctually moves from the standpoint of viewing nature in terms of particulars, to viewing them as concepts, since "things have truth only 
as concepts." ${ }^{, 52}$ The richest understanding of nature would be to postulate particulars in the form of a universal concept, i.e. the universal concept of teleology.

In the parallel argument dealing with the law of teleology in the section on "Reason," Reason sublates the sensuous being of the law of teleology, and isolated things in nature are conceived conceptually as a whole system of interrelated parts. The concept of the organic whole, or the objective law of teleology, is thus when consciousness views the relation of natural objects as one purposeful concept. 


\section{CHAPTER III:}

\section{CONTINGENCY IN EMPIRICAL LAWS; REASON'S DEMAND FOR REGULATIVE NECESSITY}

The second aspect of Hegel's critique of Kant's law of teleology is based on the problem of contingency remaining in nature's sensible particulars for the discursive mode of understanding. For the discursive intellect, which is dependent on independently given sensible intuitions, particulars are presented as contingent. Kant's solution to the problem of contingency in nature is a superficial one, according to Hegel, because Kant does not propose the elimination of contingency in nature with the concept of teleology. For Kant, teleology is not capable of eliminating contingency in nature since such a task is beyond human capabilities. Kant's concept of teleology is dependent on his view of regarding human cognition as discursive, in which contingency in nature cannot be eliminated. He argues that human Reason has a far less demand than constitutive necessity of nature, which would mean the elimination of contingency in the way particulars are presented to us, instead Reason requires regulative necessity of concepts, which means the elimination of contingency in empirical laws.

Kant argues that Reason requires the empirical laws of nature, which are presented as contingent to the Understanding (because there are infinite possibilities of empirical laws) be unified under one common law; the law of purposiveness. The faculty of the Understanding requires nature to be lawful in order to have a coherent experience, so Judgment generates this additional principle to order the contingent empirical laws 
within itself. This unity of the contingent provides us only with conditional necessity, however, since it is restricted to subjective conditions of human cognition.

In this chapter, I will elaborate on the regulative function of Kant's principle of teleology, which does not give us constitutive necessity, but only conditional necessity in our consideration of nature. This is due to the fact that Kant attributes the source of the $a$ priori principle of purposiveness to reflective, and not determinative judgment. If purposiveness were rooted in determinate judgment, it could yield constitutive necessity and according to Hegel would be a "much higher way of envisioning purposiveness" because it would mean the constitution of necessity in nature, not just in the idea of nature.

\section{Role of Reason in Reflective Judgment}

In the Appendix to the First Critique, and his parallel discussion in the published Introduction to the Third Critique, Kant makes a critical distinction between the dual functions of Reason in determinative and reflective judgment. ${ }^{53}$ In determinative judgment, the universal (rule, principle or law) is given and judgment subsumes the particular under it. Reason in its apodeictic employment, deduces the particular from the universal. In this case, the universal is "already certain in itself and given," and the faculty of judgment is required to subsume the particular under it. ${ }^{54}$ In reflective judgment, however, the particular is given and judgment must find the universal for it. Reason in its hypothetical employment, must find the universal rule of which the particular is a consequence. Kant argues that the way in which we prove a universal rule is by investigating whether several instances of the particular follow from the rule. But he 
goes on to argue that when we adopt a universal rule as a hypothesis, we are not able to determine whether all possible consequences follow necessarily from this rule. This means that it cannot be proven that particulars follow necessarily from a hypothetical universal. The particulars of nature, which are contingent, cannot be proven to follow necessarily from the hypothetical universal of purposiveness. In the case of reflective judgement, therefore, the particular which is obtained by sense perception is certain, and the universal law of purposiveness is viewed as a concept which is problematic and "a mere idea. ${ }^{, 55}$

The universal law of teleology is an especially problematic Idea of Reason because judgment does not seek to validate the hypothesis by investigating nature. The method of induction (which is the method used by Reason in reflective judgment) usually involves making inferences from observed data, but the problem is that Kant does not allow for proof of teleology to be obtained by the method of observation, so the concept of teleology stops short at hypothesis. Kant writes in regard to the idea of teleology; "Hence the concept of an absolutely necessary being, though an indispensable idea of reason, is for human understanding an unattainable problematic concept." Consequentially, since the universal is unattainable for human understanding, the truth of the universal rule of teleology is contingent not necessary. At best, the universal can only be approximated, but never proven. Reason in this case is regulative not constitutive, since teleology does not constitute an object, but is a rule which allows us to regulate knowledge of nature and approximate empirical unity. Regulative ideas of pure reason can never be constitutive [of empirical concepts] since there is no empirical object corresponding to them. 


\section{Objective Contingency and Subjective Necessity}

In the Introduction to the Critique of Judgment, Kant emphasizes the objective contingency and subjective necessity of the law of teleology. Teleology is a subjectively necessary principle required by Reason in order to systematize the diversity of empirical laws. Reason introduces this rule as a way to order the appearances of nature (empirical concepts of the Understanding), without which, we would not be able to formulate a system of nature. It is subjectively necessary to make experience possible, but such a system is contingent objectively. Both the unity of nature (empirical laws) and the unity of experience (system of empirical laws) are objectively contingent since such unity cannot be known a priori, nor can it be proven by experience.

Hence we must think nature, as regards its merely empirical laws, as containing the possibility of an endless diversity of empirical laws that [despite being laws] are nonetheless contingent as far as we can see (i.e., we cannot cognize them $a$ priori); and it is in view of this possibility that we judge the unity of nature in terms of empirical laws, as well as the possibility of the unity of experience (as a system in terms of empirical laws) to be contingent. ${ }^{57}$

According to Kant, we experience nature in terms of particular empirical laws which are presented to our understanding as infinitely diverse, and hence, contingent. The diversity of empirical laws are not known a priori, but are empirical and dependent on experience. Reason requires that the contingency of empirical laws be systematized by a logical principle, in which case, we could postulate necessary connection of nature's products (generating subjective necessity). The Understanding requires the additional principle of purposiveness, which is supplied by judgment, to systematize such laws. This

allows us to consider the contingent diversity of empirical laws as a system of logically related concepts. The necessary principle of purposiveness does not eliminate the 
contingency of nature, however, but aids the Understanding in systematization. Systematization of empirical laws aids Reason in the formulation of bodies of knowledge. Such logical unity of contingent empirical laws Kant calls purposiveness. ${ }^{58}$

Now when we find in such a combination a law-governed unity cognized by us as conforming to a necessary aim (a need of our understanding), but at the same time as in itself [an sich] contingent, then we present this unity as a purposiveness of objects (of nature, in this case). ${ }^{59}$

The contradiction between the necessary need of human understanding and the contingency of nature's products remains. This implies that the requirement of necessity is based on purely subjective conditions, and is not taken from the object. Hegel's critique is based on the idea that Kant limits the requirement of Reason to search for a law based on subjective conditions. If the principle of teleology were based on our experience of the object instead of subjective conditions, then Reason would demand constitutive necessity, and hence, the unity of nature and unity of experience would be objectively necessary.

Kant writes in the Introduction to the Critique of Judgment that the principle of teleology is "both objective and contingent [zugleich objecktiv und zufällig]." ${ }^{, 60}$ What is meant by this assertion? What sort of objectivity does this principle achieve? The principle of teleology is contingent in the sense that there is no object corresponding to it, and hence, it cannot yield objectivity, universality or necessity. Kant is not claiming the idea of natural purpose has objective reality, but merely that it has objective validity. ${ }^{61}$ Consequentially, Kant means objective in the sense that it is abjectively valid idea which has regulative use, that it has conditional necessity (not a necessary condition for all beings), and finally, that it is universally applicable. 
First of all, it is not an objectively valid concept, but an objectively valid idea which means it has regulative use for the subject. ${ }^{62}$ The Understanding restricts the validity of the Ideas to the subject, which means that the idea of teleology does not extend beyond the subject into nature. Consequentially, the idea of teleology does not pertain to the determination of objects themselves. Kemp Smith's suggestion, which I believe to be in line with Hegel's thought, that objectively valid ideas only generate a "semi-objectivity" 63 since the referent in question is not nature, but nature within cognition.

Second, necessity is conditional because it is generated from the demand of human Reason's goal of systematicity, meaning that it does not attach to the object but to the conditions of the subject. The idea of purposiveness of nature is generated by a need of human understanding to order nature. Kant argues that even if human Reason requires such unity, this does not imply that it is a requirement for all rational beings. It is a necessary condition that attaches to the subject not the object.

This means that we would have to be willing to assert that, [merely] because we need the idea of purposes in order to study these things in their causal connection and to cognize the lawfulness in that connection, we are also justified in presupposing that every thinking and cognizing being is subject to the same need as a necessary condition, and hence that this condition attaches to the object rather than merely to our [selves, as] subject[s]. ${ }^{64}$

Purposiveness is a universal principle in the sense that it is universally applicable for all human cognition in order to generate systematicity. However, purposiveness is not a necessary condition for all rational beings, but is unique to human rationality (as far as we know). It is a necessary concept which "attaches inescapably to the human race," giving it conditional necessity. 
In sum, the universal is contingent objectively, but necessary subjectively for theoretical inquiry as a heuristic device to guide our investigation of nature. The regulative ideas are heuristic devices, ideas for the "guidance of the empirical employment of reason- ideas which reason follows only as it were asymptotically, i.e. ever more closely without ever reaching them.. ${ }^{, 66}$ The idea of teleology serves only to systematize the manifold content of the Understanding, and thereby allows us to have empirical unity only within the limits of the Understanding. In recent literature, Nicholas Rescher describes the function of the Ideas of Reason as: "the unity of reason represented by the ideas is thus in the final analysis not a factual discovery, but a methodological principle, not an output or product of inquiry, but its controlling prerequisite, as it were. ${ }^{.67}$ Teleology is not a factual discovery since it is not obtained by experience, but is a necessary methodological principle used to guide scientific inquiry.

The law of reason which requires us to seek for this unity, is a necessary law, since without it we should have no reason at all, and without reason, no coherent employment of the understanding, and in the absence of this no sufficient criterion of empirical truth. In order, therefore, to secure an empirical criterion we have no option save to presuppose the systematic unity of nature as objectively valid and necessary. ${ }^{68}$

McFarland makes an important clarification concerning this key passage. Kant does not say that we have no understanding without presupposing teleology, but that we would have no coherent employment of the Understanding. ${ }^{69}$ Without this necessary presupposition, we can still have "ordinary knowledge" but not scientific knowledge. McFarland defines ordinary knowledge as the "collection of isolated propositions and empirical generalizations. ${ }^{.70}$ Hence, in order for natural science to be possible, we must assume that the particulars of nature are not contingent unrelated material, but that nature 
contains logical necessary connection, so that we can discover regularities, formulate laws, and make classifications in natural science. The principle of purposiveness allows us to postulate how every law of nature has a logical relation to the others. It allows us to conceive of nature as a whole of experience or a systematic body of knowledge.

Despite the fact that Kant considers teleology to be a necessary principle in order to have scientific knowledge, it still has no place in natural science (meaning it is not a scientific theory) because it is a concept distinct from nature. It is a principle added to nature, meaning supplied by the subject, and is not taken from our experience of the object. Kant writes:

For purposes in nature are not given to us by the object: we do not actually observe purposes in nature as intentional ones, we merely add this concept [to nature's products] in our thought, as a guide for judgment in reflecting on these products. $^{71}$

This additional principle is required purely for the purposes of systematization of knowledge. The aim of purposiveness [or systematicity] $]^{72}$ is to bring unification of knowledge of the Understanding under a single principle which the Understanding itself does not supply. It seeks to "secur[e] the greatest possible systematic unity in the empirical employment of reason." ${ }^{.73}$ In doing so, the contingent diversity in nature becomes a comprehensible system of knowledge. Systematic unity is not referring to real things themselves, however, only analogon of real things, i.e., the schema of sensibility. ${ }^{74}$ The schema have a functional role of securing the greatest possible unity but this does not imply, however, that unity is inherent in the object itself. Since it is an additional principle used as an aid in our reflection upon nature, and does not pertain to the thing itself, it cannot be considered scientific in the proper sense. 


\section{Quasi- A Priorism}

The principle of teleology is assumed a priori to be necessarily inherent in objects, but $a$ priori justification of the objective reality of the concept of teleology is impossible to determine. ${ }^{75}$ It has its a priori basis in reflective judgment for the purposes of our investigation of the possibility of experience (i.e. reflection on the cognition of nature) allowing us to connect particular empirical laws and create order among nature's appearances. "This harmony of nature with our cognitive power is presupposed a priori by judgment, as an aid in its reflection on nature in terms of empirical laws. ${ }^{, 76}$ Otherwise, universal laws will be left undetermined securing no unity among them and not allowing for the possibility of a system of nature:

Hence the purposiveness of nature is a special a priori concept that has its origin solely in reflective judgment. For we cannot attribute to natural products anything like nature's referring them to purposes, but can only use this concept in order to reflect on nature as regards that connection among nature's appearances which is given to us in terms of empirical laws. ${ }^{77}$

The principle of teleology as an a priori principle of reflective judgment is required for the basis of unity of all empirical principles. This principle is not abstracted from investigation of nature nor imposed on nature, but allows us to regulate appearances of nature, and hence, the subordination of empirical principles in a systematic way. If Kant had assigned the a priori principle to determinative judgment, the objective reality of the principle could be determined. In the next chapter we will explore Hegel's alternative, in which he assigns the principle true a priori status. The Idea, or inner purposiveness, is a concept which is determined before experience, but is discoverable $a$ posteriori. The fundamental difference between Kant and Hegel hinges on this point. Giving teleology a priori status makes objective necessity possible. 


\section{Unresolved Contradiction of Necessity and Contingency}

As stated previously, if our understanding were intuitive, particulars would not be presented to us as contingent because for such an intellect there is no distinction between necessity and contingency. Particulars are generated out of complete spontaneity from concepts, that is, they follow necessarily from the universal. So for an intuitive understanding, purposiveness is a universal and necessary concept in which all particulars can be subsumed under it. This means that the whole of nature, including sensible particulars, could be explained by the universal theory of teleology.

On the other hand for the human discursive mode of understanding, the distinction holds between necessity and contingency. Since knowledge of particulars comes to us through sense perception, the particular in nature is presented to human understanding as contingent. For Kant, since human understanding is discursive, there is no possibility to eliminate contingency in the way we experience particulars. The contradiction between contingency in nature, and Reason's requirement for necessity is not resolved by Kant's regulative principle of teleology. The contingency in the way we experience nature's particulars contradicts with Reason's requirement for a necessary principle to order those particulars. Kant's superficial solution to the problem of the contradiction between necessity and contingency is not the elimination of contingency in particulars, but the elimination of contingency in empirical laws.

Hence, the contradiction between necessity and contingency in nature is not resolved. The result of this contradiction is that from the finite point of view nature will always be presented as contingent. The unity of nature is a concept that is contingent in itself, meaning that it is objectively contingent in relation to nature and is only necessary 
in the sense that it creates subjective unity. Only in theoretical science can necessity be generated, but this necessity is not constitutive of the object, only regulative for knowledge. Kant's regulative concept of teleology will never extend into nature, and hence, cannot generate constitutive necessity. The necessity that is generated by the law of teleology is conditional because it is dependent on human requirements, it does not depend on the constitution of the object itself. 


\section{CHAPTER IV:}

\section{CONTINGENCY OF PARTICULARS;}

\section{REASON'S DEMAND FOR CONSTITUTIVE NECESSITY}

In the previous chapter, we have discussed the regulative function of Kant's principle of teleology which employs Reason's concept of teleology as a heuristic device to generate regulative necessity of nature's concepts. This is due to the fact that Kant assigns the principle of teleology to reflective and not determinative judgment, which means that its aim of necessity is based on subjective conditions. The role of Reason in reflective judgment is to regulate inquiry, so it requires that contingent empirical laws be unified in order to have a coherent experience of nature. Hence, based on a need of human understanding to unify empirical concepts, judgment produces an additional principle to order them. The result of imposing this maxim on judgment is the logical unification of empirical concepts. While Kant attributed the source of the a priori principle to reflective judgment, which employs this principle as a heuristic device to regulate inquiry, Hegel attributes the source of the a priori concept to Reason in its constitutive employment (comparable to determinative judgment in Kant).

Hegel's first main criticism of Kant's principle of teleology was that it established an irreducible contingency between Reason and nature. For Kant, the referent of teleology is not nature, but nature within cognition, which is wholly independent (and hence, contingent) from the nature of things and does not even pertain to the construction

of nature at all. Hegel's second main criticism stems from the first in that Kant's purely subjective principle, which is wholly independent from nature, does not address 
contingency in nature, but merely contingency in the concept of nature. For Kant, Reason requires regulative necessity of concepts in order to meet the subjective demand of eliminating contingency in empirical laws, but for Hegel, teleology would be a much more comprehensive theory if it were based on impressions from the object, not merely subjective conditions. Hegel argues that if Kant had envisioned the role of Reason to be constitutive instead of regulative in its application, it would be capable of postulating actual unity in nature (objective necessity), not just in the idea of nature (subjective necessity).

According to Hegel, objective necessity of teleology is an important concept which is not only useful, but necessary in natural science. Natural science begins with observation of the contingent features of nature given to us by sense perception, but the Instinct of Reason requires that we go beyond this stage of knowledge in order that the whole of nature (including sensible particulars) be completely rationalized or explained. ${ }^{78}$ The Instinct of Reason (des Vernunftinstinkt) is Hegel's metaphorical proxy for Reason/God which brings nature into conformity with Reason despite the apparent contingency in nature. By employing the constitutive function of Reason to the concept of teleology, Reason's conception of nature is instinctually driven beyond the limited standpoint of empirical consciousness, which perceives nature by means of contingent sensible particulars, to a teleological conception of nature, in which consciousness comprehends particulars by means of purposiveness (necessary connection).

In this chapter, I will elaborate on the constitutive function of Reason in Hegel's concept of teleology. Des Vernunftinstinkt requires more than regulative necessity (the elimination of contingency in concepts), but rather, constitutive necessity (the elimination 
of contingency in nature). Vernunftinstinkt, or the certainty that Reason is all of reality (including nature), is what motivates consciousness to move beyond the ineliminable contingency in the epistemological stage of observation (or empirical science) in order that the whole of nature, including sensible particulars, become rationalized.

\section{Constitutive Role of Reason}

According to Kant, there are dual functions of Reason depending on whether Reason is employed in reflective or determinative judgment. Kant assigns teleology to reflective judgment, in which case, the regulative function of Reason is employed. As a regulative device, Reason seeks to order the empirical concepts of nature. Reason's aim in its regulative function, therefore, is to approximate empirical unity.

According to Hegel, if Reason were used in its constitutive employment, the concept of teleology would be much more comprehensive, since the universal would extend beyond hypothetical inquiry into the constitution of natural objects. The universal, as such, would be determined into particularity and constitute unity in nature (what Hegel calls the "concrete universal." Consequentially, when the principle is applied in its constitutive employment, no aspect of nature, not even contingent sensible particulars, would be left unexplained.

Hegel's universal law of teleology is not hypothetical and unrelated to nature as it was for Kant, but rather, it is "directed to a knowledge of the universal aspect of Nature, a universal which is also determined within itself..." which essentially means that the

universal is related to particulars in nature. ${ }^{79}$ Hegel's notion of the concrete universal functions like the synthetic universal of the intuitive understanding. Just as particulars 
follow necessarily from the synthetic universal supplied by an intuitive intellect, the particular would also follow necessarily from the concrete universal. In both cases, particulars are simultaneously generated from the universal, and hence, the particular can be deduced (or explained) from the universal.

Hegel grants human beings some of the powers associated with the intuitive intellect, which Kant conceived as being capable of explaining particulars from the universal. For the discursive intellect, contingency of nature's particulars cannot be explained away by the concept of teleology, that is, the particular cannot be deduced from the universal. In this case, the particular as such remains contingent (contingency of particularity is irreducible). Only in an intuitive understanding can the concept of teleology postulate the elimination of contingency of particulars. The problem is, that for Kant, the intuitive intellect is a regulative concept merely used to guide inquiry, but its constitutive function is not attributed to human understanding. Hegel writes in regards to the intuitive understanding:

The principle of an intuitive understanding is ascribed to the reflecting faculty of judgment; i.e., an understanding in which the particular, which is contingent for the universal ([i.e., the] abstract identity) and cannot be deduced from it, would be determined through this universal itself. ${ }^{80}$

Hegel is arguing that Kant should have attributed the intuitive understanding to the determining faculty of judgment in order that judgment can produce a constitutive concept of teleology. In an intuitive understanding, the particular is deduced from the universal (the particular follows necessarily from the universal). This is because the particular as such is a product of its intuiting and is spontaneously generated from the universal. Hegel asserts that if the intuitive intellect were attributed to determinative 
judgment, it would be capable of generating a constitutive concept which would explain contingency in nature. In such a case, the universal concept of teleology would simultaneously generate the particular, and hence, particulars in nature could be explained because the particular as such would be determined through the universal.

\section{Objective Contingency and Objective Necessity}

Hegel's critique of Kant's principle of teleology is that it generates regulative necessity (the law that orders contingent empirical laws), but does not address contingency in nature. Hegel is arguing that Kant dodges the fundamental issue of the problem of contingency of particulars (objective contingency), and proposes a superficial solution by taking refuge in maxims of reflective judgment, in which case, Reason in its regulative employment generates mere subjective necessity.

In the section "Observing Reason" (Beobachtende Vernunft) of the Phenomenology, Hegel is arguing that Reason seeks itself in nature. For the Observing Consciousness, nature is not yet understood as rational because nature is seen as distinct from Reason. The Instinct of Reason is Reason's certainty that it [Reason] is all of reality. Therefore, there cannot be a part of reality which is not rational, including sensible particulars (which are presented to observation as contingent). Therefore, the Instinct of Reason demands that we go beyond observation, beyond mere regulative necessity, in order that particulars be explained. Hence, Reason demands for more than regulative necessity of Reason's concepts, it demands constitutive necessity of nature's products. 


\section{Objective Contingency}

From the standpoint of both a discursive intellect and Observing Reason, ${ }^{81}$ there is contingency in nature's products (objective contingency). When we intuit nature by means of sense perception, there is an apparent contingency and indifference between Reason's conceptual activity and what is being observed in nature. Hence, from this standpoint, consciousness makes the distinction between the necessary concept of teleology and the contingency of nature. As we saw in Kant's case, the principle of teleology (because it was merely regulative) could only generate subjective necessity despite the appearance of objective contingency in nature's products.

The Observing Consciousness makes a distinction between what it is and what it seeks; Reason's concepts seem to be opposed to nature, and hence, nature is not understood as a rational concept, but merely as contingent sensible particulars. From the point of view of Observing Reason, consciousness obtains knowledge of nature's products through sense perception. An opposition is established from the point of view of observation in which nature seems to be independent from Reason. Reason and nature seem to be self-sufficient and indifferent to each other, each with a distinctive content of their own. Hence in this relationship, teleology is considered objectively contingent in relation to Reason because nature is opposed to Reason. The concept appears to be contingent and external to consciousness because it is intuited as a thing which seems to be indifferent towards Reason. ${ }^{82}$ This is the immediate and external form of the concept

of teleology, i.e., external teleology. ${ }^{83}$ In this external determination of consciousness, the two terms, the concept of purpose and thinghood, are externally related. 
The particular as such, will always remain contingent for the Observing Consciousness as well as for the discursive intellect, which views nature in terms of independently given sensible intuitions. This is clear from Kant's statements in the Critique of Judgment: "Nature and its form are contingent." ${ }^{84}$ And furthermore:

For the fact that our understanding has to proceed from the universal to the particular has the following consequence: In terms of the universal [supplied by the understanding] the particular as such, contains something contingent. ${ }^{85}$

Since the universal, which is supplied by the understanding, is distinct from the particular, which is given to us by the object by means of sense perception, the particular will always be presented as contingent. Such contingency cannot be eliminated if we remain at this stage of epistemology. Hegel agrees in the ineliminability of contingency at this stage of knowledge. From the standpoint of observation, the particular as such will always be presented as contingent since consciousness distinguishes between subjective concepts and the object.

The contradiction of the Idea, arising from the fact that, as Nature, it is external to itself, is more precisely this: that on the one hand there is the necessity of its forms which is generated by the Notion, and their rational determination in the organic totality; while on the other hand, there is their indifferent contingency and indeterminable irregularity. ${ }^{86}$

This excerpt from the Philosophy of Nature, emphasizes the contradiction between necessity and contingency at the empirical stage of knowledge. The Idea or internal purposiveness is the rational structure which seems to contradict what we experience in nature's products which are presented to consciousness as indifferent, irregular, and contingent.

This immediately concrete thing is a group of properties, external to one another and more or less indifferently related to each other; and for that very reason, the simple subjectivity which exists for itself is also indifferent and abandons them to 
contingent and external determination. This is the impotence of Nature, that it preserves the determinations of the Notion only abstractly, and leaves their detailed specification to external determination. ${ }^{87}$

The "impotence of nature" is Hegel's term for the empirical moment of understanding in which there seems to be an irreducible contingency in nature. "This confusion of contingency, caprice, and disorder, with freedom and rationality is characteristic of sensuous and unphilosophical thinking." 88 As we immediately experience nature by means of sense perception, nature's properties do not seem to be necessarily related. Consciousness interprets sensory stimuli as a contingent determination, and Reason's concept which unifies the object is considered to be independent from nature. This apparent contradiction, or the contingency in nature's products (impotence of nature), is what Hegel is trying to overcome with his constitutive principle of teleology. Rational determinations are more than abstractions (as in Kant's case), but are concepts concerning the determination of things themselves. Kant's external teleology is a rational concept which is purely hypothetical, and so concerns hypothetical empirical unity only. At best, it succeeds in unifying contingent empirical laws, but Kant's notion of Reason does not extend into nature itself.

\section{The Instinct of Reason and Objective Necessity}

Kantian teleology meets the subjective demand of Reason to generate regulative necessity of the contingent laws of nature, but for Hegel, necessity is based on more than subjective conditions. Reason demands more than subjective necessity of psychological laws, but instead, objective necessity of sensible particulars. Hegel reaches this conclusion on the basis of the metaphor he develops in the Phenomenology: The Instinct 
of Reason (des Vernunftinstinkt). ${ }^{89}$ The Instinct of Reason demands that we go beyond the empirical standpoint in order to eliminate contingency in the way we understand nature. Reason's instinct is based on the fundamental assumption that the certainty and truth of Reason [is that] "Reason is certain of being all reality." ${ }^{, 90}$ Consciousness is certain that Reason or necessity permeates all of realty, and hence, that Reason exists in nature (even though it [Reason] first discovers nature as contingent). When we engage in scientific inquiry, the Instinct of Reason has "...not as the certainty of entering into what is merely other, but rather with the certainty of being this other itself." ${ }^{91}$ That is, when we observe nature, Reason is certain that what it is looking at in nature is really Reason itself. Hegel's fundamental claim is that there is only an apparent difference between what it [consciousness or Reason] is and what it seeks [nature], a distinction which natural scientists uphold. Consequentially, from the standpoint of empirical science the concept of purpose is not understood as constitutive at this level of thinking. Hegel writes; "However, in this being, observing consciousness does not take cognizance of the concept of purpose. ${ }^{.92}$

Reason thus now has a universal interest in the world because it is the certainty of having its present moment in the world, that is, is certain that the present is rational. It seeks its other, since it knows that it possesses nothing else in that other but itself, that is, it seeks only its own infinity. ${ }^{93}$

Reason craves a deeper understanding of nature than contingent, unrelated bare particulars. Reason is instinctually driven beyond the contingent appearances of nature given to us by sense perception towards knowledge of conceptual (logical) necessity of nature's products. Reason begins with observing the world it first finds nature to be distinct from and "other" than itself. But its instinct is that the otherness of nature is 
really itself. Reason is on a quest for self-consciousness, self-discovery, seeking its own infinity. The present moment, that is, the appearance of organic life, is what he means by the present being rational; since the organic is in fact, for Hegel, the purpose of nature itself.

\section{Solution to the Contradiction of Necessity and Contingency?}

Hegel's constitutive concept of teleology does not resolve the contradiction between necessity and contingency in the sense that the contradiction still exists for empirical observation. At this stage of consciousness, contingency is ineliminable. ${ }^{94}$ Nonetheless, when judging nature in terms of teleology (given the power of an intuitive understanding), nature could be conceived as logically necessary, and hence, the contradiction could be sublated- but only when superseding the previous stage of inquiryin transitioning from physics to a theological conception of nature.

For a discursive mode of understanding, the contradiction between necessity and contingency holds. Hegel objects that Kant's recourse to maxims (the regulative employment of Reason's concept of teleology) leaves the fundamental contradiction between necessity and contingency in place. Hegel is in agreement with Kant, that there is a contradiction between necessity (of the notion) and contingency (of particulars), but only from the standpoint of observation.

It is not for observing consciousness that it is no distinction; rather, what it for observing consciousness is an activity which appears to be contingent and indifferent towards what is brought about by that activity and also towards the unity which ties both of them together- to observing consciousness, that former activity and this latter purpose come undone from each other. ${ }^{95}$ 
The constitutive concept of teleology resolves the contradiction by positing the identity of Reason and nature. The distinction between Reason's concept of teleology and nature is only apparent because when consciousness moves beyond empirical science to a theological conception of nature, the distinction is sublated (not eliminated entirelydifference is preserved within identity). The constitutive concept of teleology postulates unity between Reason and nature in organic life, and hence, the resolution to the contradiction between necessity and contingency lies in the organism. The unity that was absent for the observing consciousness, that is, between Reason's conceptualizing activity and nature, is constituted by the concept of teleology. The necessity generated by Reason no longer contradicts the contingency in the way we view sensible particulars because necessity of Reason extends beyond subjective theorizing into objectivity. Reason is empirically present in nature as organic life, and hence, the rational concept of teleology is expressed in nature itself.

\section{A Posteriori Approach to Knowledge}

Hegel's criticism against Kant's quasi-a priori approach to understanding nature is that it is inadequate at explaining the logical structure of nature's forms. Since Kant attributes the a priori to reflective and not determinative judgment, Hegel does not considered it a true a priori principle capable of predicting laws of nature. A priori concepts which are rooted in reflective judgment are merely for the purposes of reflecting on the object and do not guarantee logical necessity of nature's products. Hegel gives the principle of inner purposiveness true a priori status in order to guarantee that natural products do in fact have an inherent logical structure which determines them. 
Inner purposiveness (or the Idea), is an a priori concept of Reason which is discoverable a posteriori in our investigation of nature. According to the a posteriori interpretation ${ }^{96}$ of Hegel's Philosophy of Nature, the a priori which is the necessary foundation for natural science is revealed a posteriori in our experience of nature. Evidence of an a posteriori reading of Hegel can be seen when we analyze the part of the Phenomenology that discusses "revealed contingency" and "hidden necessity" in the epistemological stage of observation.

However, the essence of their relation is something other than they themselves seem to be, and their activity has another sense than it has as it immediately exists for sensuous perception. The necessity lies within what happens; it is hidden, and it first shows itself at the end. ${ }^{97}$

From the point of view of observation, Reason is not yet aware that the concept of purpose exists in reality as organic life. That is, when we consider nature in terms of scientific observation, we have a partial glimpse of necessity, but there is still a contingent aspect until we move to the level of Spirit. This is where the metaphor of the Instinct of Reason comes into play. Nature is presented to observing Reason as contingent and the necessary concept of teleology or purposiveness is "hidden" in nature (Reason is hidden in the empirical object). What Hegel meant by hidden is not entirely clear, but he seems to be implying that sometimes nature behaves in ways that are not entirely predictable, and hence, that there is a part of nature which does not appear entirely rational (the logic has not completely unfolded). The most fundamental presupposition of Hegelian thought is that logic is the ground of nature, and hence, logical categories are able to predict natural categories despite the apparent contingency and irrationality of certain features. Since Reason is considered the logical ground of 
nature, Hegel is arguing that it will ultimately be revealed to us as we continue our investigation.

Upon further investigation, Hegel writes about the current state of affairs, the emergence of human self-consciousness whereby Reason realizes that the purpose it was seeking in nature is really its own existence; i.e., organic life. Only in organic life are beings able to become self-conscious of existence itself and reflect on that process. The following quotes demonstrate Hegel's belief that the organic element is the end (telos) purpose of nature:

For reason, the organic thing is merely purpose in itself such that the necessity belongs outside of the bounds of the organic itself, that is, it is a necessity which presents itself as concealed within the thing's activity, since what is acting therein conducts itself as an indifferent existent-for-itself. ${ }^{98}$

Furthermore:

When regarded more closely, this determination turns out to lie just as much in the concept of the thing, that is, it turns out that the thing is in itself the purpose. Specifically, it maintains itself, i.e. it is its nature to conceal the necessity and at the same time present that necessity as a contingent relation. ${ }^{99}$

According to recent commentator Jean Hyppolite, in each of our judgments we get a partial glimpse of the a priori structure (i.e., inner purposiveness or the Idea) in nature. In Hyppolite's words, "Reason exists in organic nature, and it exists imperfectly...reason, which observes and which seeks itself, in part discovers itself in nature, but only in part... [and therefore] in nature reason is contingent." ${ }^{\prime 100}$ I must reiterate that the appearance of contingency in nature only applies to the epistemological stage of observation, not to teleology. The universal concept of teleology is partially revealed in sense perception, but the transition to Spirit is necessary in order that we extend knowledge beyond the contingent features of reality (in order to conceive the full nature 
of thought; sensuous and conceptual). The empirical feature of reality is not completely absorbed by Reason at this stage, but requires a transition to a higher stage of knowledge. Once the empirical stage is sublated (aufheben- both superseded and preserved therein), the a priori structure will be revealed and contingency in nature explained.

There is debate in recent Hegelian scholarship whether what is revealed $a$ posteriori affects the a priori foundations (which is another topic that deserves separate attention). In recent scholarship, Mure, I think rightly suggests, that Hegelian philosophy does not intend to completely eliminate or absorb the empirical moment (the particular and contingent) because this is an important stage of knowledge. I would not go as far as Mure, however, in suggesting that the a priori structure is contingent. ${ }^{101}$ Hyppolite's standpoint, that nature is partially contingent and partially necessary has far more textual support than Mure's (that Reason is empirical and contingent). The following text demonstrates that Hegelian ontology presupposes an ontological structure a priori and in the empirical investigation of nature the rational structure is being revealed.

But if reason rummages around through all the innards of things, and opens all their veins so that reason might encounter itself gushing out from them, then it will have no luck; rather, it must have at an earlier point perfected itself in itself in order to be able to experience its perfection. ${ }^{102}$

In Hegelian ontology, the a priori concept (the Idea or inner purposiveness) precedes nature and determines nature, despite the apparent contingency in empirical observation. Since the a priori structure (Reason or God or Logic) is already perfected before experience, the fact that natural science still exhibits contingency merely means that science is not yet completed. Once science is complete then the a priori structure will be revealed. Croce writes that Hegel's concept "should manifest itself in the theories of 
the physicists and naturalists, in which the speculative concept would be in some measure anticipated. ${ }^{, 103}$ In a sense, Hegel seems to be anticipating that a theological conception of nature is the next stage in epistemology which will be able to explain all features of reality, and hence, go beyond the contingency remaining in natural science. 


\section{CHAPTER V:}

\section{THE ROLE OF HEGELIAN TELEOLOGY IN NATURAL SCIENCE}

This chapter will indicate the significance of Hegel's reformulation of Kant's regulative principle into a constitutive principle for scientific inquiry. Hegel's constitutive conception of teleology is significant in that it serves as a transition or bridge between natural science and theology creating a dialogue between the two bodies of knowledge.

\section{Inadequacy of Empirical Science}

Hegel's treatment of the limitations of natural science essentially states that scientific accounts of nature contain partial truth in that they describe the contingent features of nature, but he argues that contingent descriptions are inadequate because they do not capture the full features of reality (i.e., the necessary, logical aspect). In other words, there is a logical gap in the way we perceive nature's products from the standpoint of natural science. Such a disenchanted picture of nature portrays natural forms as sensible, non-rational, and meaning-less. The force of Hegel's picture of nature is that it puts meaning and rationality back into scientific inquiry.

Hegel's Philosophy of Nature especially emphasizes that our thinkingconsiderations of nature, even physics, has a conceptual aspect that needs to be emphasized. In the Introduction to the Philosophy of Nature, Hegel treats the relationship between physics and the philosophy of nature. He assigns physics as belonging to the sphere of empirical science, or perception and experience, and philosophy of nature to the sphere of thought (what he calls rational physics). Hegel's 
main point in this section is that physics "contains much more thought than it admits and is aware of." ${ }^{\prime 104}$ Physics and rational physics are both thinking apprehensions of nature and this is a fundamental point because it means that from the standpoint of empirical science, nature is more enchanted or spiritual than it seems to be. The standpoint of rational physics understands nature as more than contingent, isolated and indifferent content, but as logically related material. His point is that scientists see natural forms as non-rational and disenchanted, while Hegel views nature as intrinsically rational. "The method of physics does not satisfy the Notion, that we have to go further.",105

In Hegel's re-enchanted picture of nature, natural forms are understood as rational and developing from a logically necessary structure. Hegel is essentially claiming that his rationalist metaphysics of nature is more adequate at explaining natural forms than the metaphysics presupposed in physics (that matter is dead, or consists of bare particulars).

If we examine a flower, for example, our understanding notes its particular qualities; chemistry dismembers and analyses it. In this way we separate colour, shape of the leaves, citric acid, etheric oil, carbon, hydrogen, etc.; and now we say that the plant consists of all these parts...but even if we put together all those ingredients of the flower the result is still not a flower. ${ }^{106}$

Hegel's point here is that in empirical science, objects are conceived as isolated, indifferent, and contingent, and the spiritual link that ties them together is missing. ${ }^{107}$ In our philosophy of nature, he argues that sensible intuitions alone do not capture the full features of nature (sensual and conceptual). Sensible intuitions must also be unified by concepts. He writes; "Spirit cannot remain at this stage of thinking in terms of detached, unrelated concepts (Verstandesreflexion)." ${ }^{\prime 108}$ Sensible intuitions require a universal concept which unifies isolated parts (in this case, the parts of the flower) in order to conceive of the whole object conceptually. His point with the flower metaphor is to 
demonstrate that physics incorporates more thought that was previously considered. Matter itself is more than dead, bare particulars, but is already conceptual and meaningfull. The same applies to nature as a whole. The constitutive concept of teleology is the universal concept which unifies the parts of nature to form a conception of the organic whole.

\section{Teleology and Modern Science}

Hegel envisaged a more comprehensive natural science which included a theological conception of nature. Re-contextualizing natural science (in terms of a theology) would include the interpretation of natural scientific findings within a philosophical framework (an absolute idealist philosophical framework). Consequentially, such an understanding of science would allow us to go beyond empiricism in order to include not only contingent empirical descriptions of reality, but also, a logical rational description.

In an age where natural science dominates theoretical inquiry, Hegel's scientific conception of teleology signifies the usefulness of God as an explanatory principle in science, not only as a heuristic device (Kant), but as a theory about the nature of reality. Hegel's scientific teleology essentially serves as an apology for a theological conception of nature because he derives the concept of teleology based on the same method used in empirical investigation. Hegel's "scientific teleology" makes it possible for God to be part of our scientific investigation of nature without recourse to an unreachable realm. In scientific teleology, the purposiveness of natural forms are not based on a transcendent, unobservable God, but rather, an immanent God which is inherent in experience. The term "God" is not being used by Hegel in the contemporary sense, but is a technical term 
he uses interchangeably with "Reason," "logic" or "necessity." Hegel's scientific theory of teleology essentially claims that Reason (necessity or logic) is immanent in natural forms (i.e., constitutive of the object). Kant's regulative principle of teleology is only making a claim about logical necessity and systematicity of concepts. Hegel asserts that Kant's maxim, which constituted subjective unity and necessity, ignored the contingencies of nature.

Why did Hegel believe that constitutive teleology was more useful in natural science than regulative teleology? Hegel asserts that Kant`s principle of teleology is limited because it is not scientific, and thus, it fails to give an explanation of necessity of particulars of nature. For Hegel, the theory of teleology is not merely a subjective maxim and a way of understanding nature, but is a theory about the ontology of objects themselves. Hegel viewed his constitutive concept of teleology as significant in the sense that it served as the bridge or transition between science and religion, a transition which Kant considered to be impossible.

For Kant, science and theology have no dialogue and one cannot serve as the basis for the other. In Section 68 in the Critique of Judgment, "On the Principle of Teleology as a Principle Inherent in Natural Science," Kant treats the relationship between teleology and physics. He asserts that the concept of God has no place as an explanatory principle in natural science. ${ }^{109} \mathrm{He}$ starts with the fundamental assumption that "every science is a system in its own right..." and that we must "treat it as a whole and independent building, not as an annex or part of another building, though we may later construct, starting from either building, a passage connecting the one to the 
other." ${ }^{110}$ Essentially, he views physics and theology as two distinct bodies of knowledge, and hence, teleology cannot serve as a basis for natural science.

Kant bases his refutation on a distinction he makes between two approaches to knowledge. In the first approach, all the principles of the particular science are inherent in it and are called indigenous (principia domestica). In the second approach, the principles of the science are based on principles outside that particular science and are called foreign (principia peregrina). In the second case, a concept is taken from one scientific body of knowledge and used as the basis for another. Thus, to introduce God into natural science would be to introduce a foreign principle, and hence, make both sciences "uncertain." Kant does not allow the boundaries of science and theology to overlap. Consequentially, a theological derivation of natural objects is therefore inadmissible. Kant makes an interesting comment, however, that natural science cannot make the leap into theology until we have "completed natural science."111 Does this imply that when science is "completed" then natural science might require recourse to theology?

Arithmetic analogies or geometric ones, or also universal mechanical laws, no matter how strange and admirable may seem to us [the ability] to unify in one principle [their] different and seemingly quite independent rules, still cannot on that account claim that they can serve as bases for teleological explanations in physics. ${ }^{112}$

Kant finds the teleological way of judging natural objects to solve problems of physics inadmissible. Kant argues that when the principle of teleology, which is taken from theology, is used as the basis for scientific inquiry, this belongs to meta-physics, not physics proper. 
On the contrary, Hegel did not view science and theology as distinct bodies of knowledge, but rather, as stages in the development of knowledge. For Hegel, the theological conception of nature follows natural science and in a sense completes science by going beyond the contingent empirical descriptions of nature. It is important to note that Hegel does not intend to replace science with theology, but instead, extend science by incorporating theology as an additional framework to explain the construction of natural objects. Hegel's scientific teleology does not require recourse to religious cults which are based on unobservable phenomena, but in keeping with the scientific method, teleology begins with observation and experience (it begins with physics).

Science is both necessary- to describe contingent features of natural forms- but problematic- in that its descriptions are invariably inadequate...Hegel thinks that the proper response to this inadequacy is not to transform radically- and so, in effect, destroy- science but instead to engage in ongoing reinterpretation of scientific findings in terms of rationalist metaphysics. He does not envisage science's abolition, but its relocation within the more all-encompassing context of a philosophical form of inquiry into nature. ${ }^{113}$

For Hegel, a theological explanation of nature is not only useful in natural science, but it is also necessary because it makes science more comprehensive. Hegel's rationalization project goes beyond contingencies remaining in the empirical explanation of nature and it also goes beyond Kant's project of the systematization of empirical concepts (which only accomplishes subjective necessity). Hegel views his constitutive concept of teleology as more adequate than Kant's because it accomplishes the task of explaining the contingency in natural forms. 


\section{CHAPTER VI:}

\section{INADEQUACY IN HEGEL'S LEAP FROM NATURAL SCIENCE TO THEOLOGY}

Hegel argues that his rationalist metaphysics is more comprehensive than scientific metaphysics in explaining nature. Allison Stone argues that Hegel's argument from "explanatory power" and his argument from "systematic derivation" are both unsuccessful defenses of Hegel's rational metaphysics. ${ }^{114}$ Stone argues that Hegel's rationalist metaphysics of nature only succeeds in formal strength in avoiding logical dilemmas (since it eliminates the logical gap in our consideration of natural forms). I would argue, however, that it has more than formal strength because what Hegel means by "necessity" is not merely an epistemological claim, but an ontological claim. The necessity that is "hidden" within empirical experience, is both logical necessity and ontological necessity. The logically necessary structure (the Idea or inner purposiveness) precedes nature, and determines nature. Hence, in our empirical investigation of nature the a priori structure is actually revealed a posteriori. Hegel is essentially making an ontological claim about the necessity of natural forms in existence.

I agree with Stone's second claim which states that Hegel's explanation of the transition from the logical structure of reality into natural forms is inadequate. Hegel's argument from systematic derivation succeeds in giving a sound defense of his metaphysical system of absolute idealism (although I am not convinced that he proved in the Phenomenology why all other rival systems are inadequate). Despite that, Hegel's argument fails to prove how the logical structure actually transitions into nature. In my 
reading, Hegel cannot adequately defend the derivation of natural forms from pure thought-forms or logic. The defense Hegel gives for this transition in the Phenomenology is based on his metaphor of the Instinct of Reason, which bases the transition from natural science to theology on an instinct to go beyond contingent explanations to a logically necessary explanation. The question remains to be answered, however, how can the transition from natural science to theology be based on an "instinct" and still be defensible?

Hegel's metaphor of the Instinct of Reason is vulnerable to serious criticism since it assumes the identity of Reason and nature, and hence, in my view is unsuccessful in guaranteeing the leap from natural science to theology. The instinct of Reason is driven by the fundamental assumption that it [Reason or God] permeates all of reality. An ineliminable contingent feature would imply that one aspect of reality were not touched by God or Reason, and hence, would imply that God were a false infinite. This is comparable to the idea of Divine Providence, in which, despite the deeds of humanity, God's Will will eventually be done on earth. The Instinct of Reason presupposes that necessity is implicit in natural forms, and consequentially, that the completion of natural science should display that necessity. In other terms, Hegelian ontology presupposes that the a priori logical structure will be revealed to us in our a posteriori investigation of nature. The Instinct of Reason is the guarantee that Reason will manifest itself in our empirical investigation of nature. Only because of this presupposition is Hegel able to guarantee the correspondence between the structure of nature and the structure of Reason. 


\section{PRIMARY SOURCE INDEX}

\section{Georg Wilhelm Friedrich Hegel}

D The Difference Between Fichte's and Schelling's System of Philosophy, transl. H.S. Harris, ed. H.S. Harris and Walter Cerf (Albany: State University of New York Press, 1977).

EL The Encyclopedia Logic, transl. T.F. Geraets, W.A. Suchting, and H.S. Harris. The translation is from the third edition published in 1830 with Zusätze (additions) (Indianapolis: Hackett Publishing, 1991).

FK Faith and Knowledge, transl. Walter Cerf and H.S. Harris (Albany: State University of New York Press, 1977).

PhG Phenomenology of Spirit, transl. Terry Pinkard. Online draft: http://web.mac.com/titpaul/ Site/Phenomenology_of_Spirit_page.html (2010). The translation is based on 1807 edition of Phänomenologie des Geistes.

PN Philosophy of Nature, transl. A.V. Miller and forward by J.N. Findlay. The translation is from Nicolin and Pöggeler's edition (1959) and from the Zusätze in Michelet's text (1847) (Oxford: Clarendon Press, 1790).

\section{Immanuel Kant}

CJ Critique of Judgment, transl. Werner Pluhar. The translation is from the second edition of Kritik der Urtheilskraft, published in 1793 (Indianapolis: Hackett, 1987).

CPR Critique of Pure Reason, transl. Norman Kemp Smith. The translation is from the second edition of Kritik der reinen Vernunft published in 1787 (Palgrave Macmillan, 2007). 


\section{TEXT NOTES}

1 Hegel, Clark Butler and Christiane Seiler transl. Hegel: The Letters (Bloomington: Indiana University Press, 1984), p. 35-36.

${ }^{2}$ Hegel, Georg Wilhelm Friedrich, Faith and Knowledge, transl. Walter Cerf and H.S. Harris (Albany: State University of New York Press, 1977), paraphrased from CJ. §76 (Hereafter, FK).

${ }^{3}$ Kant, Immanuel, Critique of Judgment, transl. Werner Pluhar (Indianapolis: Hackett, 1987), §77. (Hereafter, CJ).

${ }^{4}$ CJ. $\S 77$.

${ }^{5}$ Hegel, Georg Wilhelm Friedrich, The Difference Between Fichte's and Schelling's System of Philosophy, transl. H.S. Harris, ed. H.S. Harris and Walter Cerf (Albany: State University of New York Press, 1977), 164/104. (Hereafter, D).

${ }^{6}$ CJ. $\$ 77$.

${ }^{7}$ CJ. $\$ 77$.

${ }^{8}$ Hegel assimilates our understanding of the organism with the intuitive intellect's understanding of nature. Both the organism and nature are seen as self-determined concepts, that is, they maintain themselves and do not require any additional feature for their production. Just as in the organism, nature determines itself from its own concept, no external determination is required. In regards to nature, in Kant's idea of an intuitive intellect and Hegel's concept of the Idea, the universal determines itself out of its own immanent necessity. In the case of an intuitive understanding, particulars are simultaneously generated from the universal. Likewise, in the case of the Idea, nature (particularity) is simultaneously generated from the universal idea of purposiveness. In both cases, nature is understood as a whole system (as opposed to parts) which is self-preserving, self-contained and self-produced (like the organism). Hegel writes, "The outstanding merit of the Critique of Judgment is that Kant has expressed in it the notion and even the thought of the Idea. The notion of an intuitive understanding, of inner purposiveness, etc., is the universal concurrently thought of as concrete in itself. It is only in these notions that Kant's philosophy shows itself to be speculative." Refer to Hegel's Encyclopedia Logic, transl. T.F. Geraets, W.A. Suchting, and H.S. Harris (Indianapolis: Hackett Publishing, 1991), §55. (Hereafter, EL); and the Introduction to Hegel's Philosophy of Nature, transl. A.V. Miller and forward by J.N. Findlay (Oxford: Clarendon Press, 1790), \$246. (Hereafter, PN).

${ }^{9}$ CJ. $\$ 77$.

${ }^{10} \mathrm{CJ} . \S 76$.

${ }^{11}$ CJ. $\$ 76$.

${ }^{12}$ CJ. $\$ 76$.

${ }^{13}$ CJ. $\$ 74$, p. 278.

${ }^{14}$ Hegel, Georg Wilhelm Friedrich, Phenomenology of Spirit, transl. Terry Pinkard. Online draft: http://web.mac.com/titpaul/Site/Phenomenology_of_Spirit_page.html (2010), §259. (Hereafter, PhG).

${ }^{15}$ Hegel is not awarding the human intellect all powers of the intuitive intellect, only some. For instance, human understanding is not given the power to generate objects from the mere intuition of them. Hegel is not granting human beings the power of God, who presumably has the ability to cause nature by thinking it. In Hegel's view, human beings are not gods in the sense that we cannot be the cause of the world, but rather, that our intellect views knowledge in a similar respect to the intuitive intellect. Eckart Förster points out that there is a distinction between Kant's idea of an intuitive intellect and an intuitive understanding and the two terms are often mixed because Kant goes back and forth between them. The idea of an intuitive intellect, which proceeds from "synthetic universal" to particulars does not necessarily imply that such an intellect possesses the causal powers of a divine mind or a divine understanding. See Eckart Förster's articles, "Significance of $\S 76$ and 77 of the Critique of Judgment for the Development of Post-Kantian 
Philosophy. Graduate Faculty Philosophy, Part I. Vol. 30 No. 2 (Nov., 2009) and Part II, Vol. 31, No. 2 (Nov., 2010).

16 For Kant's discussion of the distinction between discursive and intuitive understanding see especially the Third Critique, \$76, and for Hegel's appropriation of these concepts see his essay's Faith and Knowledge, transl. Walter Cerf and H.S. Harris (Albany: State University of New York Press, 1977); and The Difference Between Fichte's and Schelling's System of Philosophy, transl. H.S. Harris, ed. H.S. Harris and Walter Cerf (Albany: State University of New York Press, 1977). For further discussion of Hegel's adoption of the Intuitive Intellect, see Sally Sedgwick's book Hegel's Critique of Kant: From Dichotomy to Identity, Chapter 1, "Introduction to Hegel's Critique: Intuitive versus Discursive Forms of Understanding in Kant's Critical Philosophy," and Chapter 2 "Organic Unity as the 'True Unity' of the Intuitive Intellect," (Oxford, 2012).

${ }^{17}$ CJ. $\$ 77$.

${ }^{18}$ EL. $\$ 58$.

${ }^{19}$ PhG. $\$ 242$, brackets added.

${ }^{20} \mathrm{PhG}$. §246, brackets added.

${ }^{21}$ CJ. $\$ 74$.

${ }^{22}$ CJ. $\$ 74$.

${ }^{23}$ CJ. $\S 74$, see footnote 10 .

${ }^{24}$ Teleological judgments are not synthetic a priori judgments according to the Third Critique. There is a discrepancy if we compare Kant's discussion of the regulative Ideas of Reason in the First Critique, which are synthetic a priori and the regulative principle of teleology in the Third Critique, which is non-empirical a priori (a priori rooted in reflective judgment). Since teleological judgments are neither empirical nor analytic principles, it may seem as if they were synthetic a priori. The question remains to be answered whether the concept of teleology belongs under the category of the synthetic a priori. This depends on if Kant attributed teleology to Reason, as in the First Critique, or to regulative judgment, as in the Third Critique. Refer to Kant's Critique of Pure Reason, "Appendix to the Transcendental Dialectic: The Regulative Employment of the Ideas of Pure Reason," transl. Norman Kemp Smith (Palgrave Macmillan, 2007). (Hereafter, CPR); and the Published Introduction to Kant's Critique of Judgment, (Sect. IV and V).

In a brief but fruitful correspondence with Paul Guyer he suggested that in either case teleological judgments are not actually knowledge, and therefore, not actually synthetic a priori knowledge. So regardless if Kant changed his view regarding the classification of this principle between critiques, it would still hold that teleology is not synthetic a priori (personal correspondence with Paul Guyer, Oct. 2013). In Kant's Critique of Judgment, Part I: Critique of Aesthetic Judgment, Kant does classify judgments of taste as synthetic a priori, meaning that the connection of pleasure with an object is a posteriori but the assertion of the universal validity of the pleasure is a priori, and based on an a priori principle (CJ. §35-37). So by parity, he should have said that teleological judgments are in some sense synthetic a priori, especially judgments concerning the organism. It could be said that the connection of the concept of purposiveness with our experience of the organism is both synthetic (goes beyond the subjective concept) and a priori (not given to us in experience). However, Kant may have been hesitant to consider teleological judgments concerning the organism as synthetic a priori because then he would have had to attribute synthetic a priori judgments to reflective and not determinative judgment (which would make the synthetic a priori regulative and not constitutive). In some sense teleological judgments seem to be synthetic a priori but were not actually categorized as such by Kant probably for the reasons just stated.

${ }^{25}$ Transcendental deduction of the regulative ideas of reason is impossible. In order to eliminate the contingent relationship between Reason and nature and have a theory which could yield objective knowledge, a transcendental deduction (justification) of the idea of teleology must be possible. This transcendental principle requires justification in order to have a systematic conception of nature, but no justification is possible because the idea of teleology has no objective reference. A transcendental deduction is required in order to have scientific knowledge of nature, but no strict deduction of this idea is 
possible because there is no object absolutely to which the concept refers, since it is only an object in the idea. Kant makes two comments concerning the transcendental deduction of the ideas; in the first Critique he writes that a deduction is required in order to validate them, but in the third Critique, that no deduction is possible (CPR. A664/B692 and CJ. Sect. V). The question remains why do the ideas require a deduction if they are regulative?

The theory of teleology can never be validated like the categories since the ideas are contingently related to nature. The ideas of pure reason cannot be given the same type of deduction as in the case of the categories (A 669/ B 697). The categories within the faculty of the Understanding have an objective world that gives it justification; experience validates the categories, and the categories make experience possible. Unlike the categories, however, the idea of teleology cannot be validated. The impossibility of a transcendental deduction of the ideas gives the idea of teleology only indeterminate validity. Kant writes: "the remarkable feature of these principles, and what in them alone concerns us, is that they seem to be transcendental, and that although they contain mere ideas for the guidance of the empirical employment of reason- ideas which reason follows only as it were asymptotically, i.e. ever more closely without ever reaching them- they yet possess, as synthetic a priori propositions, objective but indeterminate validity, and serve as rules for possible experience," (CPR. A 663/ B 691, italics added). The theory of teleology can only be given a "regulative deduction" (McFarland's words) which gives them subjective validity. For discussion of the impossibility of the deduction of the ideas refer to J.D. McFarland's Kant's Concept of Teleology, "The Ideas of Reason and Teleology," (University of Edinburgh Press, 1970), p. 25-29. Also refer to Henry Allison's Kant's Transcendental Idealism: An Interpretation and Defense, "The Regulative Function of Reason," (Yale University Press, 2004), p. 437-444.

${ }^{26}$ CJ. p. 237 and 288.

${ }^{27}$ CPR. p. 637-638.

${ }^{28}$ CPR. A 676/ B 704.

${ }^{29}$ CJ. $\$ 74$.

${ }^{30} \mathrm{CJ} . \S 61$.

${ }^{31}$ CPR. A 670/ B 698- A 671/ B 699.

${ }^{32}$ For a discussion of the Understanding as the object of Reason See Kant's Critique of Pure Reason, "Appendix to the Transcendental Dialectic."

${ }^{33}$ CPR. p. 550.

${ }^{34}$ CPR A 644/ B 672, italics mine.

${ }^{35}$ The categories of the Understanding and nature do not reveal the same type of contingent relationship as that between the regulative Ideas of Reason and nature. The principle of teleology, as an Idea of Reason, is not balanced by an objective world like the categories. Gerd Buchdahl describes the two relationships as follows: In the case of the Understanding, "categories and objective situation held one another in balance; experience validating the categories; and in their turn the categories making experience possible. In the case of 'reason' however, little more remains than the postulated demand for theoretical unity, i.e. systematicity, not balanced by anything 'objective." See Gerd Buchdahl's "The Relation Between the Understanding and Reason in the Architectonic of Kant's Philosophy," Proceedings of the Aristotelian Society, Vol. 67 (1996-1967), p. 209-226.

${ }^{36}$ Heautonomous principle, as opposed to an autonomous principle, means that the principle governs only itself or subjective cognition. Refer to Kant's Third Critique, p. 25.

${ }^{37} \mathrm{CJ}$. Introduction V, italics added.

${ }^{38}$ CJ. $\S 61$ and $\S 75$.

${ }^{39}$ PhG. §250, p. 221.

${ }^{40}$ PN. §246, Remark, Zusatz, p. 10. 
${ }^{41}$ PN. $\$ 246$.

${ }^{42}$ PhG. $\$ 249$, p. 220.

${ }^{43}$ D. $163 / 103$.

${ }^{44}$ PhG. §252.

${ }^{45}$ For description of the moments of the law of teleology see especially PhG. $\$ 251$.

${ }^{46} \mathrm{PhG}$. §249, italics added.

${ }^{47} \mathrm{PhG}$. 2259 , brackets added.

${ }^{48}$ PhG. §251, italics added.

${ }^{49}$ PhG. §251.

${ }^{50}$ PhG. §251.

${ }^{51}$ PhG. $\$ 91$.

${ }^{52}$ PhG. $\$ 251$ and $\$ 242$.

${ }^{53}$ Refer to Kant's consideration of regulative function of the ideas of Reason in the First Critique, specifically in his discussion of the apodeictic and hypothetical use of Reason, and his parallel discussion in the Third Critique of the function of Reason in determinative and reflective judgment (CPR. p. 534-535 and CJ. Sect. IV, respectively).

${ }^{54}$ Ibid.

${ }^{55}$ Ibid.

${ }^{56}$ CJ. $\$ 76$.

${ }^{57}$ CJ. Intro. V.

${ }^{58}$ CJ. $§ 76$.

${ }^{59} \mathrm{CJ}$. Introduction V.

${ }^{60} \mathrm{CJ}$. Intro. $\mathrm{V}$.

${ }^{61}$ CJ. §76 Comment.

${ }^{62}$ CJ. $\$ 76$ Comment.

${ }^{63}$ Norman Kemp Smith, Commentary to Kant's 'Critique of Pure Reason,' "Appendix to the Transcendental Dialectic,” (New York: Humanities Press, 1962), p. 555.

${ }^{64}$ CJ. $\$ 75$.

${ }^{65} \mathrm{CJ} . \$ 75$.

${ }^{66}$ CPR. A 663/ B 691.

${ }^{67}$ Rescher, Nicholas, Kant and the Reach of Reason: Studies in Kant's theory of Rational Systematization (University of Cambridge, 2000), p.144.

${ }^{68}$ Refer to CPR. A 651/ B 679, italics mine. Norman Kemp Smith argues that Kant's position wavers between a subjective and an objective interpretation of the Ideas of Reason, which I believe results from a confusion between Kant's dual meanings of objectivity. The passages that Smith has in mind (CPR. A 650/B 678 and A 651/B 679) Kant is not referring to an objectively valid concept, which is universal and necessary, but an objectively valid idea, which is universally valid for the subject, and has regulative use (Kemp Smith, p. 547).

${ }^{69}$ McFarland, p. 23.

${ }^{70}$ Ibid.

${ }^{71}$ CJ. $\$ 75$. 
${ }^{72}$ According to Allison, there is a difference between purposiveness and systematicity. In the Critique of Pure Reason, the regulative ideal of systematicity of empirical knowledge was previously assigned to the faculty of pure theoretical reason in its hypothetical employment. In the Critique of Judgment, Kant reassigns the regulative principle of teleology (or purposiveness) to regulate empirical knowledge to a new faculty, the faculty of reflective judgment (Allison, p. 440, FN. 33). Paul Guyer notes that this topic has not been adequately treated and most commentators generally speak of systematicity as a product of either reason or reflective judgment. Guyer argues that Kant reassigned the ideal of systematicity from reason to reflective judgment for a purpose; to complete the task of subsumption rather than Reason's own independent objective of completeness. He argues, that one of the main tasks of the Critique of Judgment was to connect the application of the categories with empirical experience. Systematicity (or the law of purposiveness in the case of judgment) was reassigned so that it could find the universal not given by the categories in order to connect the categories with experience, and hence, constitute a unity of experience (a task which we found was impossible objectively since it is a purely regulative ideal). Refer to Paul Guyer's article, "Reason and Reflective Judgment: Kant on the Significance of Systematicity," Nous, Vol. 24, No. 1, On the Bicentenary of Immanuel Kant's Critique of Judgment (March, 1990), pp. 17-43.

${ }^{73}$ CPR. p. 550.

${ }^{74}$ See especially CPR. A 665/ B 693 and A 674/ B 702.

${ }^{75}$ CJ. $\$ 75$.

${ }^{76}$ CJ. Intro. V.

${ }^{77}$ CJ. Introduction IV, italics mine.

${ }^{78}$ For a discussion of Hegel's project of rationalization refer especially to H.S. Harris, Hegel's Ladder: Vol. I. The Pilgrimage of Reason, "Instinctive Reason," (Indianapolis: Hackett Publishing, 1997).

${ }^{79}$ PN. \$246.

${ }^{80}$ EL. $\$ 55$.

${ }^{81}$ Hegel does not assimilate the discursive intellect with Observing Reason, this is my own assimilation.

${ }^{82}$ PhG. $\$ 259$

${ }^{83}$ For a discussion of the problem of immediacy in external teleology see Hegel's Encyclopedia Logic, Sect. C. Teleology, §204-212.

${ }^{84}$ CJ. $\S 61$.

${ }^{85}$ CJ. $\$ 76$.

${ }^{86}$ PN. $\S 250$.

${ }^{87}$ PN. $\$ 250$.

${ }^{88}$ PN. $\$ 250$, Remark.

${ }^{89}$ Compare Hegel's discussion of the "Instinct of Reason" in the Phenomenology and the "Cunning of Reason," which appears in the Encyclopedia and Philosophy of History. Common to both metaphors is the ability of Reason to permeate all reality, whether it be history, nature or logic. This fundamental assumption is fatal to the Hegelian system and eventually contributed to its collapse.

${ }^{90}$ PhG. $\$ 242$.

${ }^{91} \mathrm{PhG} . \S 240$, italics mine.

${ }^{92}$ PhG. $\$ 259$.

${ }^{93} \mathrm{PhG}$. $\$ 240$, second italics added.

${ }^{94}$ Contingency in nature is ineliminable, nor is it Hegel's aim to eliminate it. I reached this conclusion thanks in part to a brief correspondence with Sally Sedgwick (April- Aug 2013). In Hegel's critique of natural epistemology, it is true that in some sense he is dissatisfied with the contingency remaining in the empirical explanation of nature. At first glance it appears that he is seeking to eliminate contingency entirely from his rational theory in order that the whole of nature (including contingent particulars) become rationalized. But even if Reason, or the modal category of necessity, is meant to supersede the moment of actuality (Nature), contingency is still a necessary stage of knowledge. The role of the category of contingency is fundamental in Hegel's Logic. It can be said, that contingency is a necessary stage in the development of knowledge which is why it cannot be eliminated entirely. The transition from a contingent 
to a necessary understanding of nature is necessary in order to go beyond the inadequacies and limitations of the empirical standpoint. As a result, the contingent, empirical moment of experience (i.e. Nature or actuality) is not completely absorbed by Reason, but is incorporated as a stage in Hegel's understanding of the phenomenology of consciousness.

${ }^{95}$ PhG. $\$ 259$, italics added.

${ }^{96}$ Allison Stone suggests that there are three possible readings of Hegel's Philosophy of Nature: strong a priorism, weak a priorism, and a reformulation of the weak a priorism, or a posteriorism. Refer to Alison Stone's, Petrified Intelligence: Nature in Hegel's Philosophy (Albany, New York: State University of New York Press, 2005). Strong a priorism does not take into account empirical knowledge. In other words, this method does not incorporate scientific findings, but rather, attempts to deduce empirical results based on purely analytic principles. Nature must then somehow correspond to the forms that have been deduced $a$ priori. Criticism against strong a priorism is based on the idea that this method dismisses or rejects modern scientific findings. The weak a priori method, advocated by Petry, is one which recognizes scientific concepts, but reorganizes them so that they are compatible with the a priori structure of the logic. Petry argues that Hegel reinterprets scientific findings through the logical categories. The problem with the weak a priori method is that it absolutizes empirical claims. In this reading, since logical considerations guide Hegel's interpretation of science, what he is doing is conforming modern science to his logic. This is problematic because it will only enhance scientific findings of the present day, but does not recognize the fallibility of such scientific theories. See Hegel's Philosophy of Nature, Vol. I-III, Ed. M.J. Petry. (New York: Humanities Press, 1970).

The a posteriori reading, advocated by John Burbidge and Jean Hyppolite avoids the problems traced above. The a posteriori method holds that scientific concepts only imperfectly instantiate logical categories. If nature instantiated the logical categories perfectly, then there would be no need to explore nature at all or write a philosophy of nature to begin with. The richness of nature exceeds the logical categories, and requires an additional framework in order to organize the empirical and contingent content of nature, which therefore requires us to investigate the natural categories a posteriori. This requires an $a$ posteriori approach to natural knowledge, which makes logic partially dependent on empirical data, and hence, contingent on experience. This means that Hegel's a priori foundation (i.e. the logic) would require further investigation of nature in order to complete the logic. Refer to John W. Burbidge's, Hegel's Systematic Contingency "The Necessity of Contingency," (New York: Palgrave Macmillan, 2007); and Jean Hyppolite's Genesis and Structure of Hegel's Phenomenology of Spirit (Evanston: Northwestern University Press, 1974).

${ }^{97}$ PhG. §257, italics added.

${ }^{98} \mathrm{PhG}$. 259 , italics added.

${ }^{99}$ PhG. 2259 , italics added.

${ }^{100}$ Hyppolite, p. 243-245, italics added.

101 Mure's interpretation of Hegel's theory of nature is not the authoritative reading, but it is certainly compelling because of its provisional character and because it implies no inherent commitment to the empirical findings of Hegel's day. In other words, the outdated empirical findings that Hegel analyzes in his Philosophy of Nature could in principle be substituted for material discovered by modern science. This means that Hegel's theory of nature would not be limited to the science of his day, and may be salvageable in this sense if we understand his approach to nature as empirical and provisional. This conclusion, however, is a double edged sword. While we may be able to incorporate recent scientific findings into this conceptual framework, this also implies that the empirical, contingent features of nature must dictate concepts at the most fundamental level. Not only would physical theories be provisional, but the logic and mathematics would not be immune to revision either. For a comprehensive account of the empirical contingent character of Hegel's logic refer especially to G.R.G. Mure's, A Study of Hegel's Logic, "Empirical and A Priori," (Oxford: Clarendon Press, 1967).

102 PhG. §241.

${ }^{103}$ Benedetto Croce, What is Living and What is Dead of the Philosophy of Hegel (London: Macmillan and Co, 1915), pp. 162-163.

${ }^{104}$ PN. Intro. Zusatz.

105 PN. p. 10. 
${ }^{106}$ PN. Introduction, §246, Remark.

${ }^{107}$ In the Introduction to the Philosophy of Nature Hegel quotes Faust, part. I, sc. 4 in order to emphasize the missing spiritual link in our theoretical inquiry into nature:

If you want to describe life and gather its meaning, To drive out its spirit must be your beginning,

Then though fast in your hand lie the parts one by one

The spirit that linked them, alas is gone

And 'Nature's Laboratory' is only a name

That the chemist bestows on't to hide his own shame.

${ }^{108}$ PN. §246, Remark.

${ }^{109}$ For a treatment of Kant's refutation of God's place in natural science refer to McFarland, p.111-116.

${ }^{110}$ CJ. $\S 68$.

${ }^{111}$ CJ. $\$ 68$, p. 262.

${ }^{112}$ CJ. $\$ 68$.

${ }^{113}$ Stone, p. 88-89.

${ }^{114}$ Stone, p. 85-106. 